- Nota -

\title{
NOVEDADES EN EL RÉGIMEN DE PREVENCIÓN Y CONTROL AMBIENTAL DE ACTIVIDADES EN CATALUÑA: RETROCESO EN LA PROTECCIÓN DEL MEDIO AMBIENTE VERSUS PROMOCIÓN DE LA ACTIVIDAD ECONÓMICA ${ }^{1}$
}

\author{
LUCÍA CASADO CASADO \\ Profesora Titular de Derecho Administrativo \\ Universitat Rovira i Virgili \\ Investigadora del CEDAT \\ lucia.casado@urv.cat
}

RESUMEN: este trabajo analiza las principales novedades del régimen de prevención y control ambiental de las actividades en Cataluña, derivadas de la aprobación de las Leyes 9/2011, de 29 de diciembre, de promoción de la actividad económica, y 5/2012, de 20 de marzo, de medidas fiscales, financieras y administrativas y de creación del impuesto sobre las estancias en establecimientos turísticos, que modifican la Ley 20/2009, de 4 de diciembre, de prevención y control ambiental de las actividades. Estas Leyes, que nacen con el objetivo de introducir medidas de promoción de la actividad económica y medidas fiscales y financieras para hacer frente a la grave situación actual de crisis económica, tienen repercusiones importantes respecto al sistema de prevención y control ambiental de las actividades y consecuencias relevantes respecto al grado de protección ambiental, sistemas de control de las actividades y estándares ambientales hasta hace poco aplicables en Cataluña.

RESUM: aquest treball analitza les principals novetats del règim de prevenció i control ambiental de les activitats a Catalunya, derivades de l'aprovació de les Llei 9/2011, del 29 de desembre, de promoció de l'activitat econòmica, i 5/2012, del 20 de març, de

\footnotetext{
${ }^{1}$ Este trabajo se ha realizado en el marco del proyecto "Derecho ambiental y libertad de servicios en el mercado interior: nuevos retos, transformaciones y oportunidades" (DER2010-19343), financiado por el Ministerio de Economía y Competitividad.
} 
mesures fiscals, financeres i administratives i de creació de l'impost sobre les estades en establiments turístics, que modifiquen la Llei 20/2009, del 4 de desembre, de prevenció i control ambiental de les activitats. Aquestes Lleis, que neixen amb l'objectiu d'introduir mesures de promoció de l'activitat econòmica i mesures fiscals i financeres per fer front a la greu situació actual de crisi econòmica, tenen repercussions importants sobre el sistema de prevenció i control ambiental de determinades activitats i conseqüències rellevants respecte al grau de protecció ambiental, sistemes de control de les activitats i estàndards ambientals fins fa poc temps aplicables a Catalunya.

ABSTRACT: This study analyzes the main new aspects of the regime for the prevention and environmental control of activities in Catalonia. These changes are the result of the approval of Law 9/2011, of 29 December, on promoting economic activity, and Law 5/2012, of 20 March, on fiscal, financial and administrative measures and on the creation of the tax on staying in tourist establishments; these laws together modify Ley 20/2009, of 4 December, on the prevention and environmental control of activities. These laws were passed in order to introduce measures to promote economic activity and fiscal and financial measures to deal with the current economic crisis, and they will have important repercussions on the system of prevention and environmental control of activities and, therefore, important consequences on the degree of environmental control, the systems for controlling activities and the environmental standards that were applicable in Catalonia until recently.

PALABRAS CLAVE: intervención administrativa ambiental, autorización ambiental, licencia ambiental, comunicación, evaluación de impacto ambiental, prevención, control ambiental

PARAULES CLAU: intervenció administrativa ambiental, autorització ambiental, llicència ambiental, comunicació, avaluació d'impacte ambiental, prevenció, control ambiental 
KEY WORDS: administrative environmental intervention, environmental authorization, environmental licence, communication, environmental impact assessment, prevention, environmental control

Sumario: I. Introducción. II. El régimen de prevención y control ambiental de las actividades instaurado por la Ley catalana 20/2009, de 4 de diciembre: aspectos generales. III. Análisis de las modificaciones introducidas por la Ley 9/2011, de 29 de diciembre, de promoción de la actividad económica. 1. Algunas reflexiones en torno a la técnica legislativa utilizada. Crítica a la utilización de una ley ómnibus para esta reforma. 2. Las razones que justifican la reforma: la promoción de la actividad económica como bandera. 3. Análisis de las modificaciones más relevantes. 3.1. Cambios en la estructura de los regímenes de intervención ambiental. 3.2. Cambios que afectan a la modificación sustancial de actividades. 3.3. La reducción del ámbito de aplicación de las mejores técnicas disponibles. 3.4. Aspectos relativos al procedimiento. A. La modificación del plazo para resolver los procedimientos de autorización ambiental de las actividades del Anexo I.1. B. La introducción de algunos supuestos de silencio administrativo positivo. 3.5. Régimen transitorio. A. La modificación de las disposiciones transitorias primera y cuarta de la Ley 20/2009. B. La introducción de dos nuevas disposiciones transitorias en la Ley 9/2011. 3.6. Otras disposiciones. IV. Análisis de las modificaciones introducidas por la Ley 5/2012, de 20 de marzo, de medidas fiscales, financieras y administrativas y de creación del impuesto sobre las estancias en establecimientos turísticos. 1. De nuevo sobre la técnica legislativa utilizada: ahora una ley de acompañamiento de los presupuestos. 2. ¿Por qué una reforma tres meses después de la anterior? 3. Análisis de las modificaciones más relevantes. 3.1. Modificaciones en el régimen de control de determinadas actividades. 3.2. Cambios en el Anexo VI. 3.3. Cambios en el régimen transitorio y en el régimen de adecuación de actividades. A. Una nueva modificación de la disposición transitoria cuarta de la Ley 20/2009. B. Nuevas previsiones en torno a la adecuación de las actividades existentes con anterioridad a la Ley 3/1998 e incluidas en los anexos de la Ley 20/2009 ¿Cierre definitivo del régimen de adecuación de las actividades preexistentes? V. Consideraciones finales. VI. Bibliografía.

\section{INTRODUCCIÓN}

A finales de 2009 se aprueba en Cataluña la Ley 20/2009, de 4 de diciembre, de prevención y control ambiental de las actividades ${ }^{2}$, que sustituye a la anterior Ley 3/1998, de 27 de febrero, de la intervención integral de la Administración ambiental ${ }^{3}$ y

\footnotetext{
${ }^{2}$ Publicada en el DOGC núm. 5524, de 11 de diciembre de 2009.

3 De conformidad con la disposición derogatoria de la Ley 20/2009, la Ley 3/1998, así como la Ley 1/1999, de 30 de marzo, de modificación de la disposición final cuarta de la Ley 3/1998, quedan derogadas. Sobre la Ley 3/1998, vid. CHOY TARRÉS, A., L'autorització i la llicència ambiental: especial referència a la gestió municipal, Barcelona, Bayer Hermanos, 2000; PONCE SOLÉ, J., "Prevención, precaución y actividad autorizatoria en el ámbito del medio ambiente. A propósito de los 
que incorpora un nuevo sistema de intervención administrativa sobre las actividades, con grandes cambios en relación con el anterior. A pesar de su aprobación en diciembre de 2009, su entrada en vigor no se produce hasta el 11 de agosto de 2010, ocho meses después de su publicación ${ }^{4}$. Esta Ley debería haber sido objeto de desarrollo reglamentario en el plazo de ocho meses desde su entrada en vigor ${ }^{5}$, pero este Reglamento aún no ha sido aprobado ${ }^{6}$.

Han transcurrido menos de dos años de aplicación de la Ley 20/2009 y del nuevo sistema de prevención y control ambiental de actividades en Cataluña, un espacio relativamente corto de tiempo en la aplicación de una Ley de gran complejidad e importancia por la temática que trata. Sin embargo, en el corto período de tiempo transcurrido desde su aprobación ha sido objeto ya de tres modificaciones. La primera se produjo pocos días después de su publicación, mediante la Ley 26/2009, de 23 de diciembre, de medidas fiscales, financieras y administrativas ${ }^{7}$, que únicamente modificó su Anexo IV. Las otras dos se han producido recientemente y han supuesto la introducción de cambios de mayor envergadura. Nos referimos a las modificaciones derivadas de la aprobación de las Leyes 9/2011, de 29 de diciembre, de promoción de la

regímenes de autorización ambiental, licencia ambiental y comunicación previa de la Ley catalana 3/1998, de 27 de febrero, de la intervención integral de la Administración Ambiental", Revista de Derecho Urbanístico y Medio Ambiente, núm. 183, 2001, pp. 147-192; SOLER MATUTES, P., "La Ley de la Intervención Integral de la Administración Ambiental de Cataluña", Revista de Derecho Ambiental, núm. 21, 1998, pp. 37-46; y VALENCIA MARTÍN, G., "Aplicación y perspectivas de futuro de la Directiva sobre prevención y control integrados de la contaminación”, Noticias de la Unión Europea, núm. 190, 2000, especialmente, pp. 170-178.

${ }^{4}$ Vid. la disposición final tercera de la Ley 20/2009.

${ }^{5}$ La disposición final primera, apartado primero, de la Ley 20/2009 preveía que el Gobierno debía aprobar el desarrollo reglamentario de esta Ley en un plazo de ocho meses contados desde su publicación oficial. La intención era clara: que a su entrada en vigor estuviese ya aprobado el Reglamento de desarrollo. Hasta la entrada en vigor del desarrollo reglamentario se preveía que serían aplicables las disposiciones reglamentarias que no contradijesen la Ley 20/2009, que no se opusiesen y que no fuesen incompatibles.

${ }^{6}$ Han existido, sin embargo, algunas propuestas de reglamento, elaboradas por el entonces Departament de Medi Ambient i Habitatge (ahora, Departament de Territori i Sostenibilitat) que, a mediados de 2010, difundió dos proyectos de Decreto para el desarrollo de la Ley 20/2009: uno mediante el cual se desarrollaba la Ley en relación con la autorización ambiental y la autorización sustantiva con evaluación de impacto ambiental y se regulaban las entidades colaboradoras (accesible en https://www.cetib.cat/media/upload/pdf//reglament-titol-ii editora 10569 2.pdf -último acceso, $29 / 5 / 2012-$ ); y otro respecto a las licencias y comunicaciones (accesible en https://www.cetib.cat/media/upload/pdf//projecte-reglament-ambiental-municipal editora $10 \quad 569 \quad$ 1.pdf -último acceso, 29/5/2012-). Estos proyectos, sin embargo, no fueron retomados por el nuevo Departament de Territori i Sostenibilitat, creado tras la celebración de las elecciones autonómicas del 28 de noviembre de 2010 y la victoria en las urnas de Convergència i Unió, siendo todavía una asignatura pendiente la aprobación del desarrollo reglamentario de la Ley.

\footnotetext{
${ }^{7}$ Publicada en el DOGC núm. 5537, de 31 de diciembre de 2009.
} 
actividad económica $^{8}$; y 5/2012, de 20 de marzo, de medidas fiscales, financieras y administrativas y de creación del impuesto sobre las estancias en establecimientos turísticos 9 . Ninguna de esta leyes nace con la finalidad exclusiva de modificar la Ley 20/2009. No se trata de Leyes de modificación de esta Ley. Sin embargo, en un contexto de reformas profundas de multitud de normas sectoriales de contenido heterogéneo, motivadas por la situación de crisis económica que padecemos en la actualidad, estas Leyes han modificado sustancialmente determinados aspectos de la Ley 20/2009, que son objeto de análisis en las páginas que siguen.

\section{EL RÉGIMEN DE PREVENCIÓN Y CONTROL AMBIENTAL DE LAS ACTIVIDADES INSTAURADO POR LA LEY CATALANA 20/2009, DE 4 DE DICIEMBRE: ASPECTOS GENERALES}

La Ley 20/2009 nace con el fin de superar algunas disfunciones de la Ley 3/1998, incorporar las innovaciones legislativas producidas en estos últimos años tanto a nivel estatal como autonómico y materializar la racionalización y simplificación administrativa de los procedimientos de intervención ambiental ${ }^{10}$. Esta Ley tiene como objeto establecer el sistema de intervención administrativa de las actividades con incidencia ambiental en el que se toman en consideración las afecciones sobre el medio ambiente y las personas y en el que se integra la evaluación de impacto ambiental de las actividades. Para ello, incorpora un régimen de intervención administrativa sobre las actividades exclusivamente ambiental. En este sentido, "continua essent una llei d'intervenció ambiental integral, però amb un abast circumscrit a les incidències que les activitats econòmiques poden tenir en el medi ambient $\mathrm{i}$ en les persones" $"$. Quedan fuera de la Ley otros aspectos como la seguridad (intervención en materia de prevención de incendios), la protección de la salud o la seguridad industrial (salvo el caso de las

\footnotetext{
${ }^{8}$ Publicada en el DOGC núm. 6035, de 30 de diciembre de 2011.

${ }^{9}$ Publicada en el DOGC núm. 6094, de 23 de marzo de 2012.

10 Sobre los motivos que justifican la reforma, vid. PERDIGÓ SOLÀ, J., CHOY TARRÉS, A. i LIGÜERRE CASALS, J., Comentaris a la Llei 20/2009, de 4 de desembre, de prevenció $i$ control ambiental de les activitats, Departament de Medi Ambient i Habitatge de la Generalitat de Catalunya, Barcelona, 2010, pp. 13-20.

${ }^{11}$ Ibídem, p. 21.
} 
actividades de riesgo de accidentes graves), cuya integración sí se preveía en la Ley $3 / 1998$, pero que ahora pasan a regularse por su normativa específica ${ }^{12}$.

En cuanto a su ámbito de aplicación, el sistema de intervención administrativa y, en su caso, el sistema de evaluación de impacto ambiental establecidos, se aplican a las actividades de titularidad pública y privada emplazadas en Cataluña, relacionadas en sus Anexos. A diferencia de la Ley 3/1998, la Ley 20/2009 no incorpora una cláusula residual en los Anexos que pueda permitir la entrada de otras actividades no expresamente contenidas pero que tengan incidencia ambiental ${ }^{13}$. Se trata de Anexos cerrados y no se prevé la aplicación de la Ley a actividades que no estén expresamente incluidas en los mismos.

La Ley 20/2009 mantiene un régimen de intervención gradual sobre las actividades en función de su incidencia ambiental, aunque incluye novedades significativas en relación con su predecesora ${ }^{14}$. Cuando se aprueba en 2009 recoge, en su artículo 7 (recientemente modificado por la Ley $9 / 2011^{15}$ ), diferentes regímenes de intervención:

-Autorización ambiental de la Generalitat con una declaración de impacto ambiental. Se sujetan a este régimen las actividades incluidas en los Anexos I. $1^{16}$ y I. $2^{17}$.

\footnotetext{
${ }^{12}$ Ibídem, p. 32. Sobre la “ambientalización” de la Ley 20/2009, vid. especialmente, pp. 21-23.

${ }^{13}$ La Ley 3/1998, recogía en su Anexo II.2, en el grupo 11, apartado 15, "Cualquier otra actividad con incidencia ambiental y que no esté incluida en el Anexo I o en el Anexo III” y la sometía a licencia ambiental municipal.
}

${ }^{14}$ La Ley 3/1998 preveía tres regímenes de intervención administrativa sobre las actividades en función de su incidencia ambiental: autorización ambiental de la Generalitat, al que se sometían las actividades del Anexo I; licencia ambiental, para las actividades del Anexo II; y comunicación, para las del Anexo III, aunque los municipios podían sustituir este régimen por el de licencia municipal de apertura si aprobaban una ordenanza a tal efecto.

${ }^{15}$ Las referencias que se incluyen en el texto al artículo 7 de la Ley 20/2009 son a su redacción originaria, antes de las modificaciones realizadas por la Ley 9/2011, con el fin de que puedan valorarse mejor los cambios introducidos cuando se analicen en el apartado siguiente.

${ }^{16}$ El Anexo I.1 incluye las actividades especificadas por la Ley estatal 16/2002, de 1 de julio, de prevención y control integrados de la contaminación. Sobre el régimen de prevención y control integrados de la contaminación en la normativa estatal, vid. AAVV, "Comentarios a la Ley 16/2002 de Prevención y Control Integrados de la Contaminación”, Revista Interdisciplinar de Gestión Ambiental, núm. 46, 2002; ALONSO GARCÍA, M. C., "El procedimiento de otorgamiento de la autorización ambiental integrada", Justicia Administrativa. Revista de Derecho Administrativo, núm. 19, 2003, pp. 5-25; BAUCELLS I LLADÓS, J. y VERNET I LLOBET, J. (coords.), La prevención y el control integrados de la contaminación, Marcial Pons, Madrid, 2004; CHINCHILLA MARÍN, C., "La autorización ambiental integrada: la Ley 16/2002, de 1 de julio, de Prevención y Control Integrados de la Contaminación", Revista Andaluza de Administración Pública, núm. 47, 2002, pp. 43-72; DOMÍNGUEZ SERRANO, J., La prevención y el control integrados de la contaminación, Montecorvo, 2003; FORTES MARÍN, A., El régimen jurídico de la autorización ambiental integrada, Ecoiuris, Madrid, 2004; GARCÍA URETA, A. (coord.), Régimen de prevención y control integrados de la contaminación, Gobierno de Aragón, Zaragoza, 2004; LÓPEZ-JURADO ESCRIBANO, F.B. y RUIZ DE APODACA ESPINOSA, A., $L a$ 
-Declaración de impacto ambiental con una autorización sustantiva, al que se sujetan las actividades incluidas en el Anexo I. $3^{18}$. En este régimen la intervención ambiental se lleva a cabo mediante la integración de la declaración de impacto ambiental o del informe ambiental en la autorización sustantiva.

-Licencia ambiental municipal, al que se sujetan las actividades incluidas en el Anexo $\mathrm{II}^{19}$, si bien los Ayuntamientos pueden establecer, en algunos casos, que algunas actividades del Anexo II se sometan al régimen de comunicación ${ }^{20}$.

-Régimen de comunicación, de competencia municipal, al que se someten las actividades del Anexo III y que, como novedad, ya no puede sustituirse por un régimen de licencia, como sucedía anteriormente, previa aprobación de la correspondiente ordenanza municipal.

-Régimen de intervención ambiental de actividades temporales, móviles y de investigación.

-Régimen de intervención ambiental en actividades de competencia municipal sectorial $^{21}$.

autorización ambiental integrada. Estudio sistemático de la Ley 16/2002, de prevención y control integrados de la contaminación, Civitas, Madrid, 2002; PERNAS GARCÍA, J.J., Estudio jurídico sobre la prevención de la contaminación industrial: la autorización ambiental integrada, Atelier, Barcelona, 2004; y REVUELTA PÉREZ, I., El control integrado de la contaminación en el derecho español, Marcial Pons, Madrid-Barcelona, 2003; VALENCIA MARTÍN, G. (coord.), Estudios sobre la prevención y control integrados de la contaminación, Aranzadi, Pamplona, 2003.

${ }^{17}$ En el Anexo I.2 se recogían las actividades no establecidas en el Anexo I.1, que se había considerado necesario someter a una autorización ambiental y a una declaración de impacto ambiental, bien por estar incluidas en el Anexo I del Real Decreto Legislativo 1/2008, de 11 de enero, por el que se aprueba el Texto refundido de la Ley de evaluación de impacto ambiental, bien por estar incluidas en el Anexo II de dicho Real Decreto Legislativo.

${ }^{18}$ En este Anexo únicamente se recogen unas pocas actividades en el ámbito de la energía y la minería.

${ }^{19}$ Este régimen se subdividía en actividades sometidas a licencia ambiental y a un proceso de decisión previa sobre la necesidad de declaración de impacto ambiental; y en actividades sometidas a una licencia ambiental sin necesidad de sometimiento a ningún proceso de evaluación de impacto ambiental.

${ }^{20}$ Vid. el artículo 7.1.d) de la Ley 20/2009. Con arreglo a este precepto (en su versión originaria), si bien las ordenanzas municipales no podían someter al régimen de licencia ambiental las actividades sujetas por la Ley 20/2009 al régimen de comunicación, los ayuntamientos sí podían establecer que algunas actividades del Anexo II sujetas al régimen de licencia ambiental, situadas en determinadas zonas urbanas y con una calificación urbanística determinada, se sometieran al régimen de comunicación. No obstante, no se podían someter al régimen de comunicación las actividades siguientes: las sometidas a decisión previa de la Administración respecto a su sujeción o no a evaluación de impacto ambiental y las sujetas a un informe preceptivo de los órganos ambientales competentes en materia de medio ambiente, en los casos determinados por los artículos 42 y 43 de la Ley 20/2009, ni las actividades ganaderas establecidas por el artículo 67 de esta Ley. 
Esta variedad de regímenes, como ponen de manifiesto PERDIGÓ SOLÀ, CHOY TARRÈS y LIGÜERRE CASALS, implica hasta diez formas y procedimientos diferentes de intervención sobre las actividades ${ }^{22}$. Estos regímenes de intervención se complementan con un completo sistema de control inicial y periódico de las actividades y de revisión, con algunas novedades significativas en relación con la Ley 3/1998, en la línea de disminuir costes y cargas administrativas.

\section{ANÁLISIS DE LAS MODIFICACIONES INTRODUCIDAS POR LA LEY 9/2011, DE 29 DE DICIEMBRE, DE PROMOCIÓN DE LA ACTIVIDAD ECONÓMICA}

La aprobación de la Ley 9/2011, de 29 de diciembre, de promoción de la actividad económica, que modifica casi una veintena de normas con rango de ley, ha tenido un impacto decisivo en el régimen de prevención y control ambiental de las actividades en Cataluña. Si bien esta Ley no significa una transformación absoluta de los regímenes de intervención administrativa establecidos por la Ley 20/2009, que se mantienen en su esencia, ni un giro radical en el modelo de intervención, sí se introducen algunos cambios importantes, como los que afectan a la estructura de los regímenes de intervención ambiental, a las mejores técnicas disponibles, al procedimiento administrativo, a los regímenes de control periódico y revisión de las autorizaciones ambientales y las licencias ambientales o al régimen transitorio, entre otros. Se trata, por otra parte, de cambios justificados por la necesidad de promover la actividad económica, en un contexto de grave crisis económica y financiera y que marcan una tendencia clara de priorización del crecimiento y desarrollo económicos en detrimento de algunas exigencias ambientales hasta ahora aplicables ${ }^{23}$.

\footnotetext{
${ }^{21}$ Estas actividades no se sujetan a la licencia o al régimen de comunicación ambiental y la intervención ambiental se realiza integrando en la resolución de la licencia sectorial de la actividad o en las condiciones establecidas para el régimen de comunicación, el informe ambiental correspondiente (vid. el art. 56 de la Ley 20/2009). Asimismo, se determina un régimen de intervención ambiental para los proyectos de equipamientos y servicios de titularidad municipal (vid. el art. 57 de la Ley 20/2009).

${ }^{22}$ PERDiGÓ SOLÀ, J., CHOY TARRÉS, A. i LIGÜERRE CASALS, J., Comentaris..., cit., p. 23.

${ }^{23}$ Los cambios de la Ley 20/2009 fueron propuestos por dos Departamentos de la Generalitat de Catalunya: el Departament de Territori i Sostenibilitat y el Departament d'Agricultura, Ramaderia, Pesca, Alimentació i Medi Natural.
} 


\section{Algunas reflexiones en torno a la técnica legislativa utilizada. Crítica a la utilización de una ley ómnibus para esta reforma}

La primera cuestión a plantear en relación con la modificación de la Ley 20/2009 por la

Ley 9/2011 es la de la técnica legislativa utilizada. La modificación de esta Ley se ha realizado a través de una de las denominadas "leyes ómnibus", aprobadas por el Parlamento de Cataluña en diciembre de $2011^{24}$. Cataluña se une así a una moda que está proliferando los últimos años, de aprobación de macroleyes que modifican decenas de normas sobre los temas más variados, que ocupan decenas de páginas de los boletines oficiales ${ }^{25}$ y que, como pone de manifiesto NOGUEIRA LÓPEZ, dificultan "el control democrático de los proyectos normativos tanto por la heterogeneidad de disposiciones que contienen como por el recurso frecuente a procedimientos de urgencia para dar curso a su tramitación" ${ }^{26}$. En efecto, la modificación de la Ley 20/2009 se realiza en el marco de una Ley, la 9/2011, cuyo objeto es la promoción de la actividad económica. Junto a la Ley 20/2009, se modifican, en una única Ley, muchas otras, tanto en el ámbito agroambiental ${ }^{27}$, como en los ámbitos económico ${ }^{28}$, sanitario $^{29}$ y del

\footnotetext{
${ }^{24}$ En el DOGC núm. 6035, de 30 de diciembre, se publican las tres leyes ómnibus: la Ley 9/2011, de 29 de diciembre, de promoción de la actividad económica; la Ley 10/2011, de 29 de diciembre, de simplificación y mejora de la regulación normativa; y la Ley $11 / 2011$, de 30 de diciembre, de reestructuración del sector público para agilizar la actividad administrativa. Inicialmente el Gobierno de la Generalitat pretendía tramitar como una ley única estas tres leyes. Por ello, a finales de mayo de 2011 presentaba el anuncio de la tramitación de un Anteproyecto de ley de simplificación, de agilidad y reestructuración administrativa y de promoción de la actividad económica. Unos días después, en el DOGC de 1 de junio se publicaba el anuncio de un período de información pública para presentar alegaciones a este Anteproyecto que finalizaría el 20 de junio y que motivó una auténtica avalancha de alegaciones (un total de 2.344). Las críticas a este Anteproyecto no se hicieron esperar, tanto por la técnica legislativa utilizada (modificación a través de una única ley, en una sola votación, de más de 80 normas) como por la intensidad de las modificaciones previstas en muchos de los ámbitos afectados. Estas críticas motivaron que finalmente el Gobierno de la Generalitat, atendiendo las peticiones de los diferentes grupos parlamentarios, decidiera dividir el Anteproyecto de Ley Ómnibus inicial en tres partes para facilitar la negociación durante su tramitación. De este modo, el Consejo Ejecutivo aprobó tres proyectos de ley para su tramitación en el Parlamento, que culminaron en la aprobación de las leyes referenciadas.

${ }^{25}$ Buen ejemplo de ello son la Ley 25/2009, de 22 de diciembre, de modificación de diversas leyes para su adaptación a la Ley sobre el libre acceso a las actividades de servicios y a su ejercicio; y la Ley 2/2011, de 4 de marzo, de economía sostenible.

${ }^{26}$ NOGUEIRA LÓPEZ, A., "Crisis económica y cambios estructurales en el régimen de ejercicio de actividades ¿Reactivación económica o pretexto desregulador", en BLASCO ESTEVE, A. (coord.), El Derecho público de la crisis económica. Transparencia y sector público. Hacia un nuevo Derecho administrativo, Instituto Nacional de Administración Pública, Madrid, 2011, p. 134.

${ }^{27}$ En el ámbito agroambiental, se modifican, además de la Ley 20/2009, la Ley 6/2001, de 31 de mayo, de ordenación ambiental del alumbrado para la protección del medio nocturno; la Ley 1/2008, de 20 de febrero, de contratos de cultivo; el Texto refundido de la Ley de protección de los animales, aprobado mediante Decreto legislativo 2/2008, de 15 de abril; el Texto refundido de la Ley reguladora de los residuos, aprobado mediante Decreto Legislativo 1/2009, de 21 de julio; la Ley 22/2009, de 23 de
} 
territorio $^{30}$, sin relación aparente con ella, todo ello bajo el mismo paraguas cobertor y tramitándose en el mismo procedimiento legislativo (por la vía de urgencia), con una única votación. En nuestra opinión, la técnica legislativa seguida merece ser objeto de crítica, habida cuenta que se regulan en un texto único las modificaciones de diversas normas con rango de ley, sobre materias muy diversas, sin hilo conductor entre ellas. Asistimos, de esta forma, a un proceso que VILLAREJO GALENDE ha denominado de “licuefacción del derecho", toda vez que el derecho de nuestra época se convierte en un "derecho líquido: inestable, complejo, degradado, cambiante, improvisado e imprevisible",31.

La utilización de leyes ómnibus ha sido objeto de crítica por la doctrina y por el propio Consejo de Estado. La doctrina se ha pronunciado en repetidas ocasiones en contra de este tipo de leyes, especialmente por lo que respecta a las leyes de presupuestos o de acompañamiento a las leyes de presupuestos, o de medidas urgentes en materia físcal, financiera, social... por afectar a un conglomerado de materias y normas diversas sin conexión entre ellas ${ }^{32}$.

diciembre, de ordenación sostenible de la pesca en aguas continentales; y la Ley 2/2010, de 18 de febrero, de pesca y acción marítimas.

${ }^{28}$ En el ámbito económico, se modifican el Texto refundido sobre comercio interior, aprobado mediante el Decreto Legislativo 1/1993, de 9 de marzo, sobre comercio interior, mediante el cual se aprueba la refundición en un texto único de los preceptos de la Ley 1/1983, de 18 de febrero, y la Ley 23/1991, de 29 de noviembre; la Ley 13/2002, de 21 de junio, de turismo de Cataluña; la Ley 8/2004, de 23 de diciembre, de horarios comerciales; la Ley 9/2004, de 24 de diciembre, de creación de la Agencia Catalana del Consumo; el Decreto ley 1/2009, de 22 de diciembre, de ordenación de equipamientos comerciales; y la Ley 22/2010, de 20 de julio, del Código de consumo de Cataluña.

${ }^{29}$ En el ámbito sanitario, se modifica la Ley $20 / 1985$, de 25 de julio, de prevención y asistencia en materia de sustancias que pueden generar dependencia.

${ }^{30}$ En el ámbito del territorio, se modifican las Leyes 12/1987, de 28 de mayo, de regulación del transporte de viajeros por carretera mediante vehículos de motor; y 18/2007, de 28 de diciembre, del derecho a la vivienda.

31 VILLAREJO GALENDE, H., "Simplificación administrativa: silencio administrativo, licencias municipales y responsabilidad patrimonial. Comentario de los artículos 40 a 42, de la Disposición adicional $8^{\mathrm{a}} \mathrm{y}$ de la Disposición final $40^{\mathrm{a}}$ ", en BELLO PAREDES, S. (dir.), Comentarios a la Ley de Economía Sostenible, La Ley, Madrid, 2011, p. 218.

${ }^{32}$ Especialmente crítica con esta técnica legislativa se muestra NOGUEIRA LÓPEZ, A., "Crisis económica...", cit., p. 136, que pone de manifiesto que "Esta práctica parece estar convirtiéndose en habitual y se aprovechan los más inusitados cauces normativos para legislar en materia económica con la urgencia de responder a los sobresaltos de los "mercados" como telón de fondo. Así se "cuelgan" de proyectos normativos que prácticamente están a punto de ver la luz en el BOE reformas que poco o nada tienen que ver con su objeto, incidiendo nuevamente en esos problemas no sólo de calidad normativa sino de debate y control democrático de las normas y de claridad para los operadores jurídicos y la ciudadanía". Vid. también el libro dirigido por esta autora, La termita Bolkestein. Mercado único vs. Derechos ciudadanos, Civitas, Madrid, 2012. 
También el Consejo de Estado, en su Dictamen 779/2009, de 21 de mayo, sobre el Anteproyecto de Ley de modificación de diversas leyes para su adaptación a la Ley sobre el libre acceso a las actividades de servicios y su ejercicio, advierte que

“(...) la técnica de las leyes "ómnibus" ha sido tradicionalmente objetada por este Consejo de Estado, particularmente exigente con la necesidad de situar cada norma jurídica o modificación de la misma en las "sedes materiae" que, presupuesta la conformación del ordenamiento en su conjunto a partir de criterios lógicos y sistemáticos, sea su ubicación normal. Desde esta perspectiva, no se considera una solución correcta ni adecuada la de incluir en una misma norma cuestiones tan diferentes y diversas como las que se regulan en el anteproyecto, habida cuenta de que "el empleo de esta técnica legislativa no hace sino aumentar la dispersión normativa existente; dispersión que dificulta la aplicación de unas normas jurídicas que tienen como destinatarios principales, no solo a autoridades, funcionarios y profesionales del derecho, sino también a particulares" (dictamen 4.908/97). Por ello debe reiterarse una vez más que razones de técnica jurídica y de buena técnica legislativa aconsejan que las normas legales nazcan en el seno propio de la materia objeto de regulación y vivan dentro de ella hasta que sean sustituidas por otras" (apartado IV).

Por otra parte, este tipo de leyes atentan contra el principio de especialización parlamentaria, ya que no pueden ser discutidas y debatidas por las Comisiones especializadas de cada materia que tratan, sino únicamente por la correspondiente a la materia del Departamento que ha preparado el Anteproyecto (normalmente Economía $\left.^{33}\right)^{34}$; y podrían vulnerar lo dispuesto por el Reglamento del Parlament de Catalunya en su artículo $101^{35}$. Con arreglo a este precepto, los proyectos y las proposiciones de ley deben tener un objeto material determinado y homogéneo y deben acompañarse de una exposición de motivos y de los antecedentes necesarios para

\footnotetext{
${ }^{33}$ En el caso de la Ley 9/2011, la Comisión competente en el Parlamento catalán para su tramitación ha sido la Comissió d'Empresa i Ocupació. Vid. el Acuerdo de la Mesa del Parlament, oída la Junta de Portavoces, en las sesiones de 6 de julio de 2011 (Butlletí Oficial del Parlament de Catalunya, núm. 119, de 22 de julio de 2011, p. 3).

${ }^{34}$ En este sentido, vid. el Informe del Ilustre Colegio de Abogados de Barcelona, de 17 de junio de 2011, que recoge las alegaciones presentadas al Anteproyecto de Ley de simplificación, de agilidad y reestructuración administrativa y de promoción de la actividad económica, p. 4.

${ }^{35}$ Así lo pone de manifiesto el Ilustre Colegio de Abogados de Barcelona, en su Informe de 17 de junio de 2011, cit., p. 6.
} 
poderse pronunciar. Y la Ley 9/2011 presenta un contenido heterogéneo y multisectorial que podría entrar en contradicción con el precepto citado. Sin embargo, el Tribunal Constitucional en la Sentencia 136/2011, de 13 de septiembre ${ }^{36}$, ha considerado que

“el dogma de la deseable homogeneidad de un texto legislativo no es obstáculo insalvable que impida al legislador dictar normas multisectoriales, pues tampoco existe en la Constitución precepto alguno, expreso o implícito, que impida que las leyes tengan un contenido heterogéneo" (FJ $\left.3^{\circ}\right)$,

y que no existe límite a su uso y contenido,

"pues la Constitución no prevé que el principio de competencia o especialidad obligue a que sólo puedan aprobarse constitucionalmente normas homogéneas que se refieran a una materia concreta. A este respecto hay que señalar que no cabe duda de que sería una técnica más perfecta la de circunscribir el debate político de un proyecto de ley a una materia específica, lo que alentaría una mayor especialización del mismo $\mathrm{y}$, posiblemente, una mejor pureza técnica del resultado. Sin embargo, los reparos que pudieran oponerse a la técnica de las leyes multisectoriales, por su referencia a un buen número de materias diferentes, no dejan de ser en muchas ocasiones otra cosa que una objeción de simple oportunidad, sin relevancia, por tanto, como juicio de constitucionalidad stricto sensu, tanto más cuanto que una y otra norma legal son obra del legislador democrático" $\left(\mathrm{FJ} \mathrm{3}^{\circ}\right)$.

En conclusión, el Tribunal Constitucional, aun aceptando que pueda ser expresión de una deficiente técnica legislativa, considera que

"del bloque de la constitucionalidad no se deriva ni impedimento alguno para que se puedan aprobar lo que califica como "leyes transversales", ni exigencia de ninguna clase que imponga que cada materia deba ser objeto de un proyecto independiente, dado que las formas de manifestarse la voluntad de las Cámaras sólo tendrán un carácter limitado cuando así se derive del propio texto constitucional" $\left(\mathrm{FJ} \mathrm{3}^{\circ}\right)$.

\footnotetext{
${ }^{36}$ Sentencia 136/2011, de 13 de septiembre (ponente: D ${ }^{a}$ Elisa Pérez Vera). Esta Sentencia resuelve el recurso de inconstitucionalidad núm. 1390-1999, interpuesto por 89 Diputados del Grupo Parlamentario Socialista en el Congreso contra determinados preceptos de la Ley 50/1998, de 30 de diciembre, de medidas fiscales, administrativas y del orden social.
} 
En cualquier caso, aunque no exista impedimento desde el punto de vista constitucional (y estatutario) para incorporar a un solo texto legislativo, para su tramitación conjunta en un solo procedimiento, multitud de medidas normativas de carácter heterogéneo, consideramos que la modificación de una Ley tan importante como la 20/2009, máxime cuando se introducen modificaciones de gran entidad en el régimen de prevención y control ambiental de las actividades, debería haberse realizado de manera diferenciada en la medida en que forma una unidad propia de gran complejidad, tramitándose como un proyecto de ley para esta materia específica, que hubiera permitido una reforma más pausada y reflexiva, con mayor discusión parlamentaria.

\section{Las razones que justifican la reforma: la promoción de la actividad económica como bandera}

La modificación de la Ley 20/2009 por la Ley 9/2011 tiene una justificación fundamentalmente económica. La Ley 9/2011 nace con el fin de reactivar la actividad económica, en una situación de grave crisis. La finalidad de la Ley, como se pone de manifiesto en su Preámbulo, es "impulsar, en el marco de la Estrategia Europa 2020, el desarrollo de la actividad empresarial, que se configura como motor de recuperación de la crisis económica mundial. Este desarrollo empresarial requiere, por un lado, la supresión de trámites y trabas innecesarios para iniciar una nueva actividad; por otro, supone otorgar valor añadido a sectores como la ganadería, el turismo y el comercio. Asimismo, implica modificaciones normativas que deben permitir llevar a cabo una política de apoyo a los empresarios catalanes".

Partiendo de estas premisas, esta Ley tiene por objeto introducir en el ordenamiento jurídico las reformas administrativas y estructurales necesarias para el impulso y la promoción de la actividad económica con la finalidad de favorecer la reactivación de la economía. En este sentido, modifica normas de rango legal de ámbitos diversos para establecer un regulación más comprensible y simplificar los trámites administrativos, con el objetivo final de facilitar la mencionada reactivación económica, y es en este contexto donde debe situarse la reforma de la Ley 20/2009. La mayor parte de modificaciones de esta Ley responden a este objetivo y buscan simplificar trámites y reducir cargas a los promotores de actividades, con el fin de dinamizar la actividad económica. No obstante, también se aprovecha esta ocasión para corregir algunos 
errores existentes e introducir algunas modificaciones en aspectos mejorables, detectados en el corto período de aplicación de la Ley 20/2009.

En definitiva, no estamos ante una reforma justificada por razones de protección ambiental, sino ante una reforma que pone la promoción de la actividad económica como bandera y que busca enérgicamente la simplificación administrativa en este ámbito, cosa por otra parte habitual en los últimos tiempos ${ }^{37}$. Sin embargo, esta reforma, como veremos, va a tener repercusiones importantes sobre el sistema de prevención y control ambiental de determinadas actividades y consecuencias relevantes respecto al grado de protección ambiental, sistemas de control de las actividades, estándares ambientales... hasta hace poco aplicables en Cataluña. En buena medida, la promoción de la actividad económica prima sobre la protección del medio ambiente y se traduce en la rebaja o disminución de determinadas garantías ambientales hasta ahora aplicables.

\section{Análisis de las modificaciones más relevantes}

El capítulo V de la Ley 9/2011 ha introducido modificaciones importantes en la Ley 20/2009, justificadas por la propia norma en la necesidad de promover la actividad económica. Con este objetivo al frente, se da un paso atrás en algunas de las normas adicionales de protección que en relación con la normativa básica estatal y la normativa europea había incorporado en su momento la Ley 20/2009, al tiempo que se flexibiliza la intervención administrativa sobre determinadas actividades y se introducen algunas mejoras en algunas cuestiones defectuosamente reguladas en la versión originaria de la Ley.

\footnotetext{
${ }^{37}$ Sirva de ejemplo el Real Decreto-Ley 17/2012, de medidas urgentes en materia de medio ambiente (BOE núm. 108, de 5 de mayo de 2012), recientemente aprobado a nivel estatal. En su Preámbulo se establece que "En una situación como la actual, en la que se están encarando profundas reformas estructurales que permitan la reactivación de nuestra economía y la generación de empleo, resulta indispensable la reforma urgente de ciertos aspectos de nuestra legislación ambiental que contribuyan a lograr ese objetivo, sin merma del principio de protección". También se afirma que la reforma "se orienta a la simplificación administrativa, eliminando aquellos mecanismos de intervención que por su propia complejidad resultan ineficaces, y lo que es más grave, imponen demoras difíciles de soportar para los ciudadanos y dificultades de gestión para las Administraciones públicas. La simplificación y agilización administrativa de las normas ambientales que se promueve, además de ser necesaria en sí misma, resulta un medio idóneo para acompañar a las reformas, que con carácter urgente, el Gobierno ha puesto en marcha". Y "Esta reforma parte del presupuesto de que la eficacia de las normas ambientales no puede identificarse con la yuxtaposición de planes, programas, autorizaciones, permisos y otras medidas de difícil aplicación real y práctica. Antes al contrario, una protección eficaz está reñida con el exceso retórico y normativo que lleva a la atrofia; y exige el establecimiento de reglas claras y sencillas que protejan el medio ambiente y fomenten un desarrollo compatible e integrado en él. En suma, la legislación ambiental también debe ser sostenible" (la cursiva es nuestra).
} 


\subsection{Cambios en la estructura de los regímenes de intervención ambiental}

Los cambios de mayor envergadura que introduce la Ley 9/2011 en la Ley 20/2009 son los relativos a los regímenes de intervención ambiental previstos en esta Ley. Son varias las modificaciones que se introducen en este sentido. En primer lugar, se modifica el régimen de autorización con evaluación de impacto ambiental establecido en su momento para las actividades del Anexo I de la Ley. Si bien se mantiene la autorización ambiental para las actividades incluidas en el Anexo I.2, ya no se exige la evaluación de impacto ambiental para todas ellas, sino que el Anexo I.2 se subdivide ahora en dos apartados: actividades sujetas a autorización ambiental con una declaración de impacto ambiental -Anexo I.2.a $)^{38}$ - y actividades sujetas a autorización ambiental y a un proceso de decisión previa sobre la necesidad de sometimiento a una evaluación de impacto ambiental -Anexo I.2.b)- ${ }^{39}$. La consecuencia es clara: muchas actividades que antes siempre requerían autorización ambiental y declaración de impacto ambiental, ahora sólo se someterán a evaluación de impacto ambiental en función del resultado del proceso de decisión previa indicado. Por lo tanto, en el caso de las actividades del Anexo I.2.b) se pasa a una evaluación caso por caso y a diferencia de lo que sucedía con anterioridad, no todas las actividades sujetas a autorización ambiental serán objeto de evaluación de impacto ambiental ${ }^{40}$.

Desaparece, de este modo, una norma adicional de protección incorporada inicialmente en la Ley $20 / 2009^{41}$, de nuevo con una justificación económica ${ }^{42}$ y de simplificación

\footnotetext{
${ }^{38}$ El Anexo I.2.a) incluye las actividades del Anexo I del Texto refundido de la Ley de evaluación de impacto ambiental de proyectos, aprobado mediante el Real Decreto Legislativo 1/2008, de 11 de enero, no sujetas a la Directiva 2008/1/CE, y también todas las actividades y las instalaciones afectadas por la legislación de accidentes graves (art. 7.1.a.1).

${ }^{39}$ El Anexo I.2.b), que recoge la mayoría de actividades del anterior Anexo I.2, incluye las actividades que se ha considerado necesario someter a una autorización ambiental y que están incluidas en el Anexo II del Texto refundido de la Ley de evaluación de impacto ambiental de proyectos, aprobado mediante el Real Decreto Legislativo 1/2008, de 11 de enero. (art. 7.1.a.2).

${ }^{40}$ En consecuencia, se modifican el artículo 7.1.a); el título del Capítulo I del Título II, que pasa de ser "Régimen de autorización ambiental con evaluación de impacto ambiental" a "Régimen de autorización ambiental" y el artículo 12, para introducir este nuevo régimen de autorización ambiental con decisión previa sobre el sometimiento a evaluación de impacto ambiental.

${ }^{41}$ En su momento, la Generalitat, yendo más allá de lo exigido por la normativa básica de evaluación de impacto ambiental, decidió establecer para determinadas actividades recogidas en el Anexo II del Real Decreto Legislativo 1/2008 (para las cuales, en principio, sólo existía obligación de consulta previa sobre la necesidad de su sometimiento a evaluación de impacto ambiental) umbrales concretos y situaciones determinadas en las cuales sería obligatorio el sometimiento a evaluación de impacto ambiental, en lugar
} 
administrativa y de reducción de cargas para el promotor de la actividad. El Consell Assessor per al Desenvolupament Sostenible ha sido especialmente crítico con este aspecto de la reforma de la Ley 20/2009. En su opinión, "en contra dels objectius de l'avantprojecte de llei, és possible que aquest procedir no afavoreixi la simplificació administrativa i suposi més càrrega per a l'administració de la Generalitat en haver de fer consulta prèvia cas per cas, si es volen seguir mantenint les suficients garanties ambientals malgrat que sí que suposi una disminució de les càrregues sobre el promotor de l'activitat, que haurà de presentar menys documentació de manera obligada. Caldrà vetllar doncs, per establir els adequats mecanismes d'equilibri entre una ajustada càrrega administrativa, i la protecció ambiental"43. Además, en cuanto al nuevo sistema de evaluación caso por caso considera que "pot subestimar el potencial impacte d'activitats que amb el procediment actual se sotmetrien al procediment complet d'avaluació d'impacte ambiental, amb majors garanties d'establir les mesures preventives i correctores pertinents" ${ }^{, 44}$.

La inclusión del trámite de decisión previa sobre el sometimiento a una evaluación de impacto ambiental para las actividades del Anexo I.2.b) trae como consecuencia la introducción de otras modificaciones en la Ley 20/2009. Entre ellas, destacan la inclusión de la decisión previa sobre el sometimiento a una evaluación de impacto ambiental entre las competencias de la Ponencia Ambiental ${ }^{45}$ y la introducción de un nuevo artículo 15bis, en el que se regula el citado procedimiento de decisión previa, con

de un simple procedimiento de consulta previa. Pretendía, de esta forma, otorgar mayor seguridad jurídica a los titulares de las actividades afectadas y eliminar la carga del procedimiento administrativo de consulta previa. Ahora, ha dado un paso atrás.

${ }^{42}$ Vid. la Memòria general de modificació de la Llei 20/2009, del 4 de desembre, de prevenció $i$ control ambiental de les activitats, elaborada por la Direcció General de Qualitat Ambiental del Departament de Territori i Sostenibilitat y que acompañaba a la propuesta de modificación de la Ley 20/2009 en el Anteproyecto de Ley ómnibus, p. 1, en la que se establece que "L'eliminació del procediment administratiu de consulta prèvia comporta l'obligatorietat d'acompanyar a la sol·licitud d'autorització ambiental de les activitats de l'annex I.2 de la Llei un estudi d'impacte ambiental amb la càrrega econòmica que comporta pel sol·licitant el cost de l'elaboració de l'estudi'”.

${ }^{43}$ Vid. Informe del Consell Assessor per al Desenvolupament Sostenible 2/2011, de 20 de junio de 2011, Consideracions sobre les modificacions previstes a l'avantprojecte de llei òmnibus en referència a la Llei 20/2009, de prevenció $i$ control ambiental de les activitats, p. 3.

${ }^{44}$ Ibidem, p. 3.

${ }^{45}$ Vid. la nueva redacción del artículo 14.1 de la Ley 20/2009. La Ponencia Ambiental es el órgano colegiado adscrito al departamento competente en materia de medio ambiente que, con la participación de todos los sectores ambientales y, en su caso, de los departamentos que se requiera de acuerdo con la actividad sectorial de que se trate, formula la declaración de impacto ambiental, la decisión previa sobre el sometimiento a una evaluación de impacto ambiental, y garantiza el carácter integrado de la autorización ambiental. 
arreglo a las previsiones del artículo 16 del Texto refundido de la Ley de evaluación de impacto ambiental de proyectos, aprobado mediante el Real Decreto Legislativo 1/2008, de 11 de enero.

En segundo lugar, también se introducen modificaciones en el régimen de licencia ambiental a que se sujetan las actividades del Anexo II. Ahora, estas actividades se subdividen en actividades sometidas a una licencia ambiental con declaración de impacto ambiental (aquellas en las que el epígrafe correspondiente del Anexo II determina específicamente que necesitan esta declaración); actividades sometidas a una licencia ambiental y a un proceso de decisión previa sobre la necesidad de declaración de impacto ambiental (son aquellas en las que el epígrafe correspondiente del Anexo II determina específicamente que necesitan este proceso); y actividades sujetas a una licencia ambiental sin necesidad de someterse a ningún proceso de evaluación de impacto ambiental.

En tercer lugar, cambia el régimen de intervención sobre las modificaciones sustanciales de las actividades relacionadas en los Anexos I.1 y I.2. Hasta ahora, la modificación sustancial de estas actividades se sujetaba a autorización ambiental con evaluación de impacto ambiental. Tras la reforma introducida por la Ley 9/2011, en cambio, el régimen aplicable es el de autorización ambiental con decisión previa sobre la necesidad de sometimiento a una evaluación de impacto ambiental, aunque la actividad requiriese declaración de impacto ambiental ${ }^{46}$-excepto en los supuestos en que sea necesaria la declaración de impacto ambiental de acuerdo con el texto refundido de la Ley de evaluación de impacto ambiental de proyectos, aprobado por el Real Decreto Legislativo $1 / 2008$, de 11 de enero ${ }^{47}$-. De nuevo se rebajan las exigencias ambientales y desaparece la obligatoriedad en todo caso, para toda modificación sustancial de actividades de los Anexos I.1 y I.2, de la exigencia de evaluación de impacto ambiental, con el fin de evitar costes a los promotores.

En cuarto lugar, se modifican los Anexos I, II y III de la Ley, en general para cambiar a la baja el régimen de intervención (por ejemplo, determinadas actividades incluidas

\footnotetext{
${ }^{46}$ Vid. los arts. 12.2 y 59.3 de la Ley 20/2009, tras la nueva redacción dada por la Ley 9/2011.

${ }^{47}$ Nótese que, de acuerdo con el Real Decreto Legislativo 1/2008, de 11 de enero, se sujeta a evaluación de impacto ambiental "Cualquier modificación o extensión de un proyecto consignado en el presente anexo, cuando dicha modificación o extensión cumple, por sí sola, los posibles umbrales establecidos en el presente anexo" [Anexo I, grupo 9, letra e)].
} 
anteriormente en el Anexo II y sujetas a licencia ambiental, pasan ahora al Anexo III y se someten a comunicación). El cambio es especialmente relevante en el caso de las actividades ganaderas, ya que excepto las incluidas en el Anexo I.1, para el resto se modifican sustancialmente los límites de la capacidad de la explotación que determinan los diferentes grados de intervención ambiental y se rebaja el régimen de intervención aplicado hasta ese momento. Así, las que estaban de forma general en el Anexo I.2, ahora pasan al Anexo II y las que estaban en el Anexo II, al III; y ello significa rebajar el grado de control a que se someten a estas actividades. Además, en el caso de las actividades ganaderas incluidas en el Anexo II, la Ley 20/2009 no permitía, en su redacción originaria, que los ayuntamientos pudiesen sustituir la licencia ambiental por un régimen de comunicación ${ }^{48}$. Con la Ley 9/2011, esta limitación ha desaparecido y es posible que los ayuntamientos puedan establecer que determinadas actividades del Anexo II, sujetas a licencia ambiental y situadas en determinadas zonas urbanas y con una calificación urbanística determinada, se sometan al régimen de comunicación, salvo que se trate de actividades sometidas a la decisión previa de la Administración respecto a su sometimiento a evaluación de impacto ambiental o sujetas a un informe preceptivo de los órganos ambientales competentes en materia de medio ambiente, en los casos determinados por los artículos 42 y 43. Todo ello conduce a que se generalice el régimen de comunicación previa para las instalaciones ganaderas de pequeña y mediana dimensión cuando la normativa europea no requiera ningún régimen autorizatorio ${ }^{49}$. De esta forma, se rebaja el grado de control al que están sometidas determinadas actividades, tanto por lo que respecta al procedimiento previo de apertura como para los controles periódicos posteriores. Con ello se busca, como se pone de manifiesto en el Preámbulo de la Ley 9/2011, "la dinamización y el aumento de la productividad del sector ganadero". Sin embargo, ello merece ser objeto de crítica ya que la generalización del régimen de comunicación ambiental para buena parte de estas

\footnotetext{
${ }^{48}$ Vid. la nota a pie de página núm. 20 de este trabajo.

${ }^{49}$ En su Memoria general de justificación de las reformas de la Ley 20/2009 propuestas, el Departament d'Agricultura, Ramaderia, Pesca, Alimentació i Medi Natural de la Generalitat de Catalunya justifica estas modificaciones en los términos siguientes: "La finalitat de la modificació de la llei 20/2009, de 4 de desembre, de prevenció i control ambiental de les activitats es justifica en traslladar a règim de comunicació en lloc de règim d'autorització ambiental, aquelles activitats ramaderes i d'aqüicultura, que no estan incloses en la normativa comunitària i estatal bàsica com de règim d'autorització prèvia. En aquest sentit, la modificació elimina aquestes activitats dels annexos I.2, I.3 i II, que passen a estar incloses en l'annex III. D'aquesta manera es deixen només aquelles activitats ramaderes que tenen una importància productiva alta, que a més són les que realment poden tenir una incidència alta des del punt de vista ambiental, alliberant a les explotacions ramaderes i d'aqüicultura restant dels tràmits inclosos en el règim d'autorització, agilitant i simplificant per tant l'obertura d'aquestes explotacions".
} 
actividades trae consigo algunas consecuencias importantes como, por ejemplo, la ausencia de controles periódicos impuestos por la Ley $20 / 2009^{50}$, sin perjuicio de los controles que correspondan en esta materia al departamento competente en materia de agricultura y ganadería ${ }^{51}$. En este sentido, consideramos acertadas las observaciones que efectúa el Consell Assessor per al Desenvolupament Sostenible en su Informe: "Cal assenyalar que en aquest règim el Departament de Territori i Sostenibilitat no exercirà cap control previ ni el seguiment dels possibles impactes de les activitats agroramaderes, que quedarà en mans dels ajuntaments i del departament competent en matèria d'agricultura i ramaderia. El CADS considera que les activitats agroindustrials $i$ ramaderes requereixen un sistema de prevenció i control ambiental estricte i efectiu, d'acord amb el seu potencial impacte ambiental, i que canviar el sistema actual caldria una sòlida motivació, cosa que no sembla pertinent actualment. La simplificació i agilització dels tràmits no es pot fer en detriment de les garanties ambientals"

Por otra parte, el paso de estas actividades del régimen de autorización o licencia ambiental al de comunicación tiene también importantes repercusiones desde el punto de vista de la participación ciudadana. En efecto, en tanto que los procedimientos de autorización ambiental y licencia ambiental cuentan con trámites de información pública por un período de 30 días y de información vecinal por un plazo de 10 días $^{53}$, no se prevé trámite participativo alguno en el régimen de comunicación.

\subsection{Cambios que afectan a la modificación sustancial de actividades}

\footnotetext{
${ }^{50}$ Recuérdese que, para las actividades del Anexo III, la Ley 20/2009 no exige, como hacía la anterior Ley 3/1998, controles periódicos (en defecto de previsión municipal específica, estos controles periódicos debían realizarse cada cinco años), sino que únicamente prevé en su artículo 73 que esta actividades "pueden someterse al régimen de autocontroles periódicos, atendiendo a la necesidad de comprobar emisiones de la actividad a la atmósfera, como por ejemplo ruidos, vibraciones, luminosidad u otros, y al agua, o la caracterización de determinados residuos, cuyo resultado se verifica de conformidad con lo que establece la ordenanza municipal" (la cursiva es nuestra).

51 El artículo 72 bis de la Ley 20/2009, introducido por la Ley 9/2011, prevé que las actividades ganaderas quedan sujetas al plan de control de la gestión de las deyecciones ganaderas y otros fertilizantes nitrogenados, que ejecuta el departamento competente en materia de agricultura y ganadería. Vid. también el apartado 2 del artículo 73.

${ }^{52}$ Vid. Informe del Consell Assessor per al Desenvolupament Sostenible 2/2011, de 20 de junio de 2011, Consideracions..., cit., p. 4.

${ }^{53}$ Vid. los artículos 20 y 41 de la Ley $20 / 2009$.
} 
Otro de los cambios que introduce la Ley 9/2011 afecta a la modificación sustancial de actividades. Por un lado, se modifica el propio concepto de "modificación sustancial", desapareciendo de la definición de tal concepto las modificaciones o las ampliaciones que impliquen un cambio del código en que ha sido clasificada la actividad ${ }^{54}$. La modificación consiste en no considerar necesariamente sustanciales las modificaciones que representen o impliquen un cambio de código; es decir, el mero cambio de código no implica per se una modificación sustancial, por lo que habrá de estarse en estos casos a los parámetros fijados por la normativa ${ }^{55}$ para determinar si la modificación puede calificarse o no como sustancial. Esta medida se justifica por el Departament de Territori i Sostenibilitat para favorecer que las actividades autorizadas puedan implantar de una manera más fácil y rápida las ampliaciones y/o modificaciones que proyecten, máxime si se tiene en cuenta que la práctica demuestra que no todos los cambios de código implican una incidencia ambiental significativa ${ }^{56}$. Tal medida tiene una implicación importante, dada la gran diferencia que existe, a nivel de tramitación procedimental, entre una modificación sustancial y una no sustancial. La modificación sustancial de actividades de los Anexos I y II se sujeta a autorización o licencia ambiental, respectivamente, y no puede llevarse a cabo mientras no se haya otorgado una nueva autorización, licencia ambiental o autorización sustantiva, de conformidad con el procedimiento determinado por la Ley 20/2009. En cambio, las modificaciones no sustanciales que tienen efectos sobre las personas o el medio ambiente sólo deben comunicarse por el titular de la actividad al órgano ambiental competente para otorgar la autorización o licencia ambientales, o bien a la Ponencia Ambiental si se trata de las actividades de los Anexos I.3 y IV; y se pueden llevar a cabo si el órgano ambiental la

\footnotetext{
54 Tras su reforma, el artículo 4.g) de la Ley 20/2009 define "modificación sustancial" como "cualquier modificación llevada a cabo en una actividad autorizada que, en aplicación de los criterios que establece el artículo 59 y de los parámetros que se determinen por reglamento, comporte repercusiones perjudiciales o importantes para las personas o para el medio ambiente".

55 Vid. el artículo 59 de la Ley 20/2009, modificado por la Ley 9/2011. Ténganse en cuenta también los criterios de calificación de las modificaciones como sustanciales o no sustanciales aprobados por la Ponencia Ambiental, en la sesión de 22 de marzo de 2011 (accesibles en http://www20.gencat.cat/docs/dmah/Home/Ambits\%20dactuacio/Empresa\%20i\%20avaluacio\%20ambien tal/Prevencio \%20i\%20control\%20dactivitats/La\%20Llei\%20de\%20prev\%20i\%20control\%20amb\%20da ct/Regim $\% 20 \mathrm{de} \% 201 \mathrm{la} \% 20$ IIAA/Criteris\%20interpretatius/documents/criteris_canvis $\% 20$ substancials $\%$ 20 _versiomarc.pdf -último acceso, 29/5/2012-).

${ }^{56}$ Vid. Memòria general de modificació de la Llei 20/2009..., cit., p. 1, en la que también se destaca que "És de vital importància aquest canvi, ja que la gran majoria d'expedients d'autorització i llicència ambientals són modificacions i/o ampliacions. D'acord amb el procediment d'implantació dels canvis no substancials que estableix l'article 59, es redueixen notòriament les càrregues administratives $\mathrm{i}$ econòmiques per l'empresa".
} 
considera no sustancial o si no manifiesta lo contrario en el plazo de un mes. Se flexibilizan, de esta forma, las exigencias inicialmente incorporadas por la Ley 20/2009, toda vez que el cambio de código de una actividad no va a implicar necesariamente la tramitación de un nuevo procedimiento de autorización o licencia ambiental. Esta medida ha sido criticada con el Consell Assessor per al Desenvolupament Sostenible, en cuya opinión no es una medida acertada eliminar de la consideración de modificación sustancial a aquella que implica un cambio de código, ya que ello significa un cambio de $\operatorname{actividad}^{57}$.

Por otro, se modifica, en los términos que ya se ha señalado con anterioridad $^{58}$, el régimen de intervención sobre las modificaciones sustanciales de las actividades relacionadas en los Anexos I.1 y I.2, que ya no se someten en todo caso a autorización con evaluación de impacto ambiental -como preveía originariamente el art. 12.2 de la Ley 20/2009-, sino a autorización ambiental con decisión previa sobre la necesidad de sometimiento a una evaluación de impacto ambiental; y se introducen algunos cambios interesantes en materia de silencio administrativo, con la introducción de algunos supuestos de silencio positivo, de los que se da cuenta en un epígrafe posterior ${ }^{59}$.

\subsection{La reducción del ámbito de aplicación de las mejores técnicas disponibles}

En relación con las mejores técnicas disponibles, la Ley 9/2011 supone un retroceso considerable. La Ley 20/2009, yendo más allá de lo estrictamente exigido por la legislación básica estatal y la normativa europea, había incorporado la exigencia de tener en cuenta las mejores técnicas disponibles no sólo para las actividades del Anexo I.1, donde era estrictamente obligatorio por tratarse de actividades sujetas a la normativa de prevención y control integrados de la contaminación, sino también, con carácter complementario, para las actividades de los Anexos I.2, I.3 y II ${ }^{60}$. Ahora se suprime del

\footnotetext{
57 Vid. el Informe del Consell Assessor per al Desenvolupament Sostenible 2/2011, de 20 de junio de 2011, Consideracions..., cit., p. 3. En idénticos términos, lo hace constar el Colegio de Ambientólogos de Cataluña, en las alegaciones presentadas al Anteproyecto de Ley de simplificación, de agilidad y reestructuración administrativa y de promoción de la actividad económica.

${ }^{58}$ Vid. el epígrafe 3.1 de este mismo apartado.

${ }^{59} \mathrm{Vid}$. el epígrafe 3.4.B de este mismo apartado.

${ }^{60}$ Sobre la incorporación de las mejores técnicas disponibles en las autorizaciones ambientales, vid. el trabajo de ESTEVE PARDO, J., "La adaptación de las licencias a la mejor tecnología disponible", Revista de Administración Pública, núm. 149, 1999, pp. 37-61.
} 
artículo 9.2 de la Ley 20/2009 toda referencia a las mejores técnicas disponibles para fijar los valores límite de emisión de las actividades de los Anexos I.2, I.3 y II, por considerarlo innecesario $^{61}$. Cae, en consecuencia, de la Ley 20/2009, otra norma adicional de protección que había sido inicialmente establecida, a pesar de no ser estrictamente obligatoria.

Por lo que respecta a la aplicación de las mejores técnicas disponibles a las actividades del Anexo I.1, la redacción de la Ley 20/2009 también ha experimentado algunos cambios destacables. En primer lugar, el artículo 9.2 impone ahora que para fijar el valor límite de emisión de estas actividades, además de la normativa en vigor en el momento de la intervención administrativa, deben tenerse en cuenta, "de forma motivada", las mejores técnicas disponibles ${ }^{62}$. Y, en segundo lugar, también se modifica la redacción del artículo 13.a) para armonizar su redacción con la del artículo 9.2 y “suavizar" la aplicación a estas actividades de las mejores técnicas disponibles. Ahora ya no se pretende con la autorización ambiental prevenir y reducir en origen las emisiones a la atmósfera, al agua y al suelo y fijar las condiciones para gestionar correctamente dichas emisiones -además de tomar en consideración el consumo de los recursos naturales y la energía-, "mediante la aplicación de las mejores técnicas disponibles", sino "teniendo en cuenta la aplicación de las mejores técnicas disponibles" ${ }^{\prime 63}$. Este cambio sutil en el redactado, como pone de manifiesto el Consell Assessor per al Desenvolupament Sostenible, puede tener consecuencias importantes en el uso estricto de las mejores técnicas disponibles. De ahí que, en su informe sobre la

\footnotetext{
${ }^{61}$ Vid. la Memòria general de modificació de la Llei 20/2009..., cit., p. 2.

62 Nótese que la Ley estatal 16/2002, de 1 de julio, de prevención y control integrados de la contaminación, en su artículo 7.1.a) también prevé que para la determinación en la autorización ambiental integrada de los valores límite de emisión "se deberá tener en cuenta" la información suministrada, de acuerdo con lo establecido en el artículo 8.1, por la Administración General del Estado sobre las mejores técnicas disponibles, pero no incorpora el añadido "de forma motivada", ahora recogido en la legislación catalana. Por otra parte, la Ley 16/2002, en su artículo 22.1.a), incluye como contenido mínimo obligatorio de la autorización ambiental integrada "Los valores límite de emisión basados en las mejores técnicas disponibles, de acuerdo con el artículo 7, para las sustancias contaminantes, en particular para las enumeradas en el anejo 3, que puedan ser emitidas por la instalación y, en su caso, los parámetros o las medidas técnicas equivalentes que los completen o sustituyan". En la doctrina se ha suscitado la cuestión de si, teniendo en cuenta la redacción de estos preceptos de la Ley 16/2002, es obligatoria o no la implantación de las mejores técnicas disponibles. Vid. por todos PERNAS GARCÍA, J.J., Estudio jurídico..., cit., pp. 239-240, que recoge diferentes posiciones doctrinales al respecto.

${ }^{63}$ Téngase en cuenta también el artículo 22.1.a) de la Ley 20/2009, que no ha sido objeto de modificación por la Ley 9/2011 y que incluye como contenido mínimo obligatorio de la autorización ambiental "Los valores límite de emisión de sustancias contaminantes, determinados de conformidad con los parámetros definidos por el artículo 9, las prescripciones de las normas europeas y, si procede, los parámetros o las medidas técnicas equivalentes que los complementan o los sustituyen".
} 
reforma de la Ley 20/2009, propusiese un refuerzo del uso de las mejores técnicas disponibles como guía para fijar los valores límite de emisión en todas las actividades que lo requieran ${ }^{64}$.

\subsection{Aspectos relativos al procedimiento}

La Ley 9/2011 modifica algunos aspectos relativos al procedimiento, tanto por lo que respecta al plazo de resolución de determinados procedimientos como al régimen del silencio administrativo.

A. La modificación del plazo para resolver los procedimientos de autorización ambiental de las actividades del Anexo I.1

La Ley 9/2001 modifica el plazo en que ha de dictarse y notificarse la resolución en los procedimientos de autorización ambiental de las actividades del Anexo I.1, que pasa de diez a ocho meses. De este modo, ahora el plazo de resolución es el mismo para las actividades del Anexo I.1 y I.2. La medida se justifica por la necesidad de facilitar y agilizar los trámites a las empresas ${ }^{65}$. Sin embargo, no pueden dejar de realizarse algunas observaciones al respecto.

En primer lugar, no queda claro si en este plazo de ochos meses se incluye también el tiempo destinado a la consulta previa de sometimiento a evaluación de impacto ambiental, que es de un máximo de tres meses ${ }^{66}$, de conformidad con la Ley 20/2009 ${ }^{67}$.

\footnotetext{
${ }^{64}$ Vid. Informe del Consell Assessor per al Desenvolupament Sostenible 2/2011, de 20 de junio de 2011, Consideracions..., cit., p. 4.

${ }^{65}$ La Direcció General de Qualitat Ambiental del Departament de Territori i Sostenibilitat de la Generalitat de Catalunya justifica esta medida en los términos siguientes: "En el context de dificultats socieconòmiques que estem vivint és important l'agilitat de tràmits administratius que facilitin l'obertura de noves activitats i la realització d'ampliacions en les existents. La reducció del termini per resoldre les autoritzacions ambientals afavorirà aquestes implantacions. Aquesta mesura, dins de les activitats de l'annex I, n'afecta a un gran nombre ja que d'acord amb les dades que disposem referents als últims 4 anys, les activitats de l'annex I.1 representen aproximadament un 72\% de tot l'Annex I'. Vid. la Memòria general de modificació de la Llei 20/2009..., cit., p. 3.

${ }^{66}$ Así lo indica el Consell Assessor per al Desenvolupament Sostenible en su Informe. Vid. Informe del Consell Assessor per al Desenvolupament Sostenible 2/2011, de 20 de junio de 2011, Consideracions..., cit., p. 4. Y también lo hace constar el Colegio de Ambientólogos de Cataluña, en las alegaciones presentadas al Anteproyecto de Ley de simplificación, de agilidad y reestructuración administrativa y de promoción de la actividad económica.
}

${ }^{67}$ Vid. el artículo 15 bis.2.b) de la Ley 20/2009. 
En segundo lugar, debe recordarse que las actividades del Anexo I.1 de la LPCAA son las que están sujetas al régimen de prevención y control integrados de la contaminación (Directiva 2008/1/CE, que sustituye a la anterior Directiva 96/61/CE; y Ley 16/2002, de 1 de julio, de prevención y control integrados de la contaminación, y Real Decreto 509/2007, de 20 de abril, que aprueba su Reglamento de desarrollo) y en este punto la legislación estatal, que fija un plazo de resolución del procedimiento de autorización ambiental integrada de diez meses ${ }^{68}$, tiene el carácter de legislación básica sobre protección del medio ambiente ${ }^{69}$. Ello plantea si la legislación catalana puede en este punto separarse de la legislación básica y establecer un plazo más reducido. En principio, resulta difícil justificar tal medida en la competencia autonómica para dictar normas adicionales de protección, pues el resultado de la misma no es un refuerzo de la protección ambiental, sino simplemente una agilización de los trámites. Además, no puede perderse de vista que la Ley estatal fija un plazo tan largo, en buena medida porque dentro del procedimiento, en los supuestos en los que la actividad sometida a autorización ambiental integrada precise, de acuerdo con la legislación de aguas, autorización de vertido al dominio público hidráulico de cuencas intercomunitarias, se prevé un trámite de informe preceptivo y vinculante del organismo de cuenca competente $^{70}$. Este informe deberá emitirse en el plazo de seis meses y, en caso de no emitirse el informe en este plazo, el órgano competente para otorgar la autorización ambiental integrada requerirá al organismo de cuenca para que emita con carácter urgente el citado informe en el plazo máximo de un mes. Teniendo en cuenta esto, el nuevo plazo de ocho meses fijado en la Ley catalana para la resolución de los procedimientos de autorización ambiental de las actividades del Anexo I.1 podría ser muy justo y plantear alguna dificultad en aquellos casos en que se trate de actividades que realizan vertidos en cuencas intercomunitarias (por ejemplo, el Ebro) o que presenten una gran complejidad. Sin embargo, cuando el proyecto no prevea vertidos a las aguas continentales o, aun previéndolos, se trate de vertidos realizados en las

\footnotetext{
${ }^{68}$ Vid. el artículo 21 de la Ley 16/2002, de 1 de julio.

69 Vid. las disposiciones finales sexta de la Ley 16/2002, de 1 de julio y tercera del Real Decreto 509/2007, de 20 de abril, con arreglo a las cuales estas normas tienen, en su totalidad, el carácter de legislación básica sobre protección del medio ambiente.

${ }^{70}$ Vid. PERDIGÓ SOLÀ, J., "La Ley estatal de transposición de la Directiva IPPC, sus efectos sobre la Ley catalana de intervención integral de la Administración ambiental, y sobre las competencias municipales”, en Revista Aranzadi de Derecho Ambiental, núm. 2, 2002.
} 
cuencas internas de Cataluña, de competencia autonómica, consideramos que la legislación autonómica puede establecer un plazo más corto ${ }^{71}$.

En tercer lugar, no puede olvidarse la realidad de la tramitación de estos procedimientos. Se trata de procedimientos de una gran complejidad técnica, con gran número de trámites e informes de otras Administraciones diferentes a la competente para resolver y con trámites participativos. Por este motivo, sin perjuicio de reconocer la agilidad que supondría para la implantación de nuevas actividades este nuevo plazo de resolución más reducido, se antoja complicado que la Administración autonómica, máxime en un momento de fuerte crisis económica y con importantes recortes económicos y de personal, pueda cumplir efectivamente con ese nuevo plazo de ocho meses, teniendo en cuenta que, según ha podido constatarse, ya era difícil conseguir resolver un procedimiento de autorización ambiental en el anterior plazo de diez meses $^{72}$.

\section{B. La introducción de algunos supuestos de silencio administrativo positivo}

El régimen del silencio administrativo en los procedimientos de autorización ambiental y licencia ambiental también experimenta algunos cambios importantes, de la mano de la Ley 9/2011. La reforma no altera el carácter desestimatorio del silencio introducido por la Ley $20 / 2009^{73}$, que, en su momento, sí significó un cambio importante en relación con la Ley $3 / 1998^{74}$. Sin embargo, sí introduce algunas novedades de interés en

\footnotetext{
${ }^{71}$ En estos términos se pronuncia PERDIGÓ SOLÀ, J., "La Ley estatal de transposición...", cit., aunque refiriéndose a la anterior Ley 3/1998, de 27 de febrero, de la intervención integral de la administración ambiental, que establecía un plazo de resolución de los procedimientos de autorización ambiental de seis meses, frente a los diez meses fijados por la Ley estatal de prevención y control integrados de la contaminación. También se considera positiva la reducción del plazo de resolución de los procedimientos de autorización ambiental a ocho meses por el Consell Assessor per al Desenvolupament Sostenible, si bien apunta que en determinados casos de gran complejidad se podría dejar un margen mayor. Vid. Informe del Consell Assessor per al Desenvolupament Sostenible 2/2011, de 20 de junio de 2011, Consideracions..., cit., p. 4.

${ }^{72}$ Nótese, de todas formas, que Direcció General de Qualitat Ambiental del Departament de Territori i Sostenibilitat de la Generalitat de Catalunya, en la Memòria general de modificació de la Llei 20/2009..., cit., p. 3, considera que "La utilització de tècniques i mitjans telemàtics ha de permetre la reducció del termini de resolució de les autoritzacions de l'Annex I.1 a 8 mesos".

${ }^{73} \mathrm{Vid}$. artículos 28.5, para los procedimientos de autorización ambiental, y 48.3, para los procedimientos de licencia ambiental.

${ }^{74}$ La Ley 3/1998 recogía un régimen de silencio administrativo positivo tanto para el régimen de autorización ambiental (al que se sometían las actividades incluidas en su Anexo I), como para el régimen de licencia ambiental (actividades del Anexo II). Ello fue objeto de importantes críticas a nivel doctrinal.
} 
este ámbito cuando se trata no de la tramitación de procedimientos de autorización o de licencia ambiental para actividades de nueva implantación, sino de procedimientos de autorización o licencia ambiental para la modificación sustancial de actividades de los Anexos I o II $^{75}$, ya autorizadas.

Cuando se trata de la modificación sustancial de actividades del Anexo I.2.b), sujetas a autorización ambiental y a un proceso de decisión previa sobre la necesidad de sometimiento a una evaluación de impacto ambiental, la autorización se considera concedida por silencio administrativo una vez transcurrido el plazo de 8 meses fijado por el artículo 28.2, si en el proceso de decisión previa se determina que no es necesaria la declaración de impacto ambiental ${ }^{76}$.

Previsiones similares se recogen en relación con la modificación sustancial de actividades del Anexo II. El nuevo artículo 59.4 de la Ley 20/2009 determina que la licencia se considera concedida por silencio administrativo una vez transcurrido el plazo máximo de seis meses fijado por el artículo 48.1, si se trata de actividades sujetas a licencia ambiental sin necesidad de someterse a ningún proceso de evaluación de impacto ambiental; o de actividades sujetas a una licencia ambiental y a un proceso de decisión previa sobre la necesidad de declaración de impacto ambiental, si en este proceso se determina que no es necesaria la declaración de impacto ambiental.

A la vista de estos nuevos supuestos de silencio administrativo positivo no pueden dejar de realizarse algunas consideraciones críticas. La justificación de la introducción de este cambio se basa en la necesidad de agilizar la implantación de actividades y simplificar la tramitación administrativa de los títulos habitantes. Sin embargo, no puede olvidarse que aun cuando se trate de la modificación de actividades ya autorizadas, son modificaciones sustanciales, que se sujetan a autorización o licencia ambiental, al igual que si fueran actividades de nueva implantación, y no pueden llevarse a cabo mientras no se haya otorgado una nueva autorización o licencia ambiental. ¿Por qué cambiar en estos supuestos el régimen de silencio administrativo? En nuestra opinión, en estos

Vid. por ejemplo, PERDIGÓ SOLÀ, J., "La Ley estatal de transposición...”, cit.; y PONCE SOLÉ, J., "Prevención, precaución...", cit., pp. 177-180.

${ }^{75}$ Con arreglo al art. 59.3 y 4 de la Ley 20/2009, tras la nueva redacción dada por la Ley 9/2011, la modificación sustancial de actividades del Anexo I está sujeta a autorización ambiental y a decisión previa sobre la necesidad de sometimiento a una evaluación de impacto ambiental o a declaración de impacto ambiental, de acuerdo con el artículo 7.1.a); y la modificación sustancial de actividades del Anexo II está sujeta a licencia ambiental de acuerdo con el artículo 7.1.c).

${ }^{76}$ Vid. el nuevo artículo 59.3 de la Ley 20/2009. 
supuestos el silencio administrativo también debería ser negativo y ello en base a varias razones, entre las que, por razones de espacio, sólo vamos a mencionar dos ${ }^{77}$. En primer lugar, tanto la autorización ambiental como la licencia ambiental están supeditadas al establecimiento de un condicionamiento previo por parte de la Administración competente en el que se fijen las condiciones en que la actividad podrá realizarse. Además, no puede olvidarse la dificultad de aplicar el silencio positivo en el ámbito de las autorizaciones en que existe un amplio grado de discrecionalidad técnica. Si bien el silencio debe ser positivo en aquellas supuestos de autorizaciones en que la resolución administrativa se limite a un pronunciamiento simplemente estimatorio o desestimatorio de la solicitud, sin más matices, no debe suceder lo mismo en aquellos otros en que se requiere una actuación positiva de la Administración por estar la estimación sujeta al establecimiento de una serie de condiciones previas. En efecto, en caso de otorgarse por silencio administrativo la autorización o la licencia ambiental, una respuesta simplemente afirmativa, un "sí", dejaría al particular solicitante en una situación de indefinición, a la par que podría peligrar el interés general. De poco vale el "sí", si no viene acompañado del "según”, “cómo”, “cuándo” y "dónde”, cuando está en juego la preservación del medio ambiente y cuando la autorización de una determinada actividad depende precisamente de la adecuación a los límites en concreto que fije la Administración sobre la base de un determinado proyecto, atendiendo al interés general y a la luz de la normativa aplicable. En segundo lugar, debe tenerse presente la regulación general del silencio administrativo contenida en la Ley 30/1992, de 26 de noviembre, de régimen jurídico de las Administraciones públicas y del procedimiento administrativo común, que excepciona la regla general del silencio positivo, entre otros, en los procedimientos cuya estimación tuviera como consecuencia que se transfirieran al solicitante o a terceros facultades relativas al dominio público o al servicio público, por lo que difícilmente podrá ser ajustado a derecho el régimen de silencio positivo en aquellos supuestos de autorizaciones o licencias ambientales que incluyan la realización de vertidos al dominio público hidráulico, al mar o al sistema público de saneamiento de aguas residuales. Por otra parte, el régimen de silencio administrativo positivo en los

\footnotetext{
${ }^{77}$ Sobre la inadecuación del régimen de silencio positivo para las autorizaciones ambientales, vid., aunque referido específicamente a las autorizaciones de vertido, CASADO CASADO, L., Los vertidos en aguas continentales. Las técnicas de intervención administrativa, Comares, Granada, 2004, pp. 261-267.
} 
supuestos analizados podría suponer la conversión de facto de la autorización o la licencia ambiental en una simple comunicación.

No obstante, a pesar de estas críticas, también debe tenerse presente que, aun siendo otorgada la autorización o la licencia ambiental por silencio positivo en los supuestos analizados, ninguno de estos títulos habilita para el ejercicio de la actividad, ya que, de conformidad con el artículo 70.2 de la Ley 20/2009, es el acta de control ambiental inicial la que habilita para ello. Además, en este punto, la jurisprudencia del Tribunal Superior de Justicia de Cataluña referida a la Ley 3/1998, ya derogada, ha venido aplicando una doctrina matizada en materia de silencio administrativo, entendiendo que el mero transcurso del plazo para resolver no determina necesariamente $\mathrm{e}$ inexcusablemente un otorgamiento la titulación administrativa pretendida, de manera que “(...) ante el mero transcurso del plazo para resolver deberá efectuarse el debido análisis de las cuestiones de fondo que se plantean para finalmente y en su caso poder llegar a la conclusión que procedía estimar la obtención de la titulación medioambiental pretendida por silencio positivo" ${ }^{, 78}$. Además, aunque fuera posible que se hubiera podido obtener una licencia ambiental por silencio, sería necesario acreditar la superación del control inicial, que es el que habilita para el ejercicio de la actividad y obstaría la orden de cese, tal y como ha establecido reiteradamente el Tribunal Superior de Justicia de Cataluña ${ }^{79}$.

\subsection{Régimen transitorio}

La Ley 9/2011 afecta al régimen transitorio previsto por la Ley 20/2009, en la medida en que modifica las disposiciones transitorias primera y cuarta. Asimismo, resultan de interés en esta materia las disposiciones transitorias primera y segunda de la propia Ley 9/2011, en la medida en que determinan, respectivamente, el régimen aplicable a los expedientes relativos a la Ley 20/2009 iniciados a la entrada en vigor de esta Ley de modificación; y el régimen transitorio aplicable a la Ley 20/2009 en relación con las actuaciones de control periódicas de las actividades ganaderas.

\footnotetext{
78 Sentencia del Tribunal Superior de Justicia de Cataluña de 29 de noviembre de 2011 (Sala de lo Contencioso-Administrativo; Sección 3aa Ponente: D Manuel Táboas Bentanachs), FJ 3.

${ }^{79}$ Vid. por todas la Sentencia del Tribunal Superior de Justicia de Cataluña de 16 de diciembre de 2011 (Sala de lo Contencioso-Administrativo; Sección 3a; Ponente: Da Ana Rubira Moreno), FJ 4.
} 
A. La modificación de las disposiciones transitorias primera y cuarta de la Ley 20/2009

La Ley 9/2011 introduce un nuevo apartado, el tercero, en la disposición transitoria primera, dedicada a los procedimientos iniciados antes de la entrada en vigor de la Ley 20/2009 y modifica también la disposición transitoria cuarta (inicialmente dedicada a las actuaciones de control periódicas y que, tras la modificación lleva por título "Régimen aplicable a determinadas actividades que ya dispongan de licencia de actividades en el momento de la entrada en vigor de la Ley"). Con estas modificaciones se introducen cambios importantes en el régimen de controles periódicos y de revisiones de las autorizaciones ambientales y licencias ambientales.

Inicialmente, la Ley 20/2009, en su disposición transitoria cuarta, se limitó a incluir algunas previsiones sobre las actuaciones de control periódicas de las actividades existentes que ya disponían de autorización o licencia ambientales con arreglo a la Ley 3/1998, en la fecha de entrada en vigor de la Ley 20/2009. Para estas actividades regían los plazos fijados para las actuaciones de control específicos de la autorización o licencia ambiental. Aunque la Ley 20/2009 había derogado expresamente la Ley 3/1998 y el nuevo régimen de intervención administrativa se limitaba únicamente a los aspectos ambientales, no determinó específicamente el régimen aplicable a los controles periódicos y revisiones de las autorizaciones y licencias ambientales ${ }^{80}$ y se limitó a determinar los plazos en que debían realizarse los controles periódicos (los fijados con arreglo a la Ley $3 / 1998)^{81}$. Ante la ausencia de desarrollo reglamentario que concretase esta cuestión, en la práctica, la Direcció General de Qualitat Ambiental del Departament de Medi Ambient i Habitatge de la Generalitat de Catalunya (actualmente, Departament de Territori i Sostenibilitat) interpretó que las actividades que disponían de autorización o licencia ambiental de acuerdo con la Ley 3/1998 pasarían a regirse en todos sus procedimientos (actuaciones de control periódico, renovaciones...) por la Ley $20 / 2009^{82}$. De este modo, los controles periódicos de las autorizaciones o licencias ambientales de actividades que habían estado sujetas a la Ley 3/1998 debían efectuarse

\footnotetext{
${ }^{80}$ Así lo destacan PERDIGÓ SOLÀ, J., CHOY TARRÉS, A. i LIGÜERRE CASALS, J., Comentaris..., cit., pp. 96-97.

${ }^{81} \mathrm{Vid}$. el contenido de la disposición transitoria cuarta de la Ley 20/2009, en su redacción originaria.

${ }^{82}$ Vid. PERDIGÓ SOLÀ, J., CHOY TARRÉS, A. i LIGÜERRE CASALS, J., Comentaris..., cit., p. 98. Vid. también el documento de la Direcció General de Qualitat Ambiental del Departament de Medi Ambient i Habitatge, “Criteris a aplicar arran de l'entrada en vigor de la Llei 20/2009 de prevenció i control ambiental d'activitats".
} 
de conformidad con el nuevo régimen jurídico (serían estrictamente en materias ambientales), si bien, serían aplicables los plazos fijados en su autorización o licencia ambiental. Este criterio provocaba una situación importante de desigualdad entre los titulares de actividades, ya que aun ejerciendo la misma actividad y aun siendo idéntico el régimen jurídico del control y de la revisión, no lo eran los plazos en que debían realizarse estos controles o revisiones. Los plazos eran mucho más estrictos para las actividades que habían estado sujetas a la Ley 3/1998 (controles periódicos cada dos años, en el caso de actividades sometidas a autorización ambiental -Anexo I-, cada cuatro años, en actividades del Anexo II.1, sujetas a licencia ambiental, y cada cinco años, en actividades del Anexo II.2, también sujetas a licencia ambiental; y revisiones periódicas cada ocho años) que para aquellas otras que desde su inicio se habían sometido a la Ley 20/2009 (en defecto de plazo específico fijado por la autorización o la licencia ambiental, controles periódicos cada dos años -actividades del Anexo I.1-, cada cuatro años -actividades del Anexo I.2- o cada seis años -actividades del Anexo II-; y revisiones periódicas cada ocho años -Anexo I.1-, cada doce años -Anexo I.2- o únicamente las revisiones periódicas que determine la legislación sectorial en materia de agua, aire o residuos -Anexo II-).

Ahora, con la Ley 9/2011, se incorpora en la disposición transitoria primera un nuevo apartado tercero. En él se prevé que el régimen de controles y de revisión de las autorizaciones ambientales y las licencias ambientales que se otorguen de acuerdo con lo que establece el apartado primero de esta misma disposición transitoria ${ }^{83}$ es el que disponen el título VIII y los artículos 62 y 63 de la Ley 20/2009. En consecuencia, aunque se trate de procedimientos iniciados antes de la entrada en vigor de la Ley 20/2009 y que se seguirán tramitando hasta su resolución por la normativa vigente en el momento de su inicio (la Ley 3/1998), el régimen de control y de revisión que se aplicará a las autorizaciones ambientales o licencias ambientales que se otorguen será el establecido por la Ley 20/2009 y no el de la Ley 3/1998, que era más estricto.

\footnotetext{
${ }^{83}$ El apartado primero de la disposición transitoria primera de la Ley 20/2009 establece que "Los procedimientos iniciados antes de la entrada en vigor de la presente Ley relativos a las actividades incluidas en los anexos I y II de la Ley 3/1998, de 27 de febrero, de la intervención integral de la Administración ambiental, que continúan incluidos en los anexos I y II de la presente Ley, se someten al régimen legal vigente en el momento en el que se inicia el procedimiento".
} 
También se modifica la disposición transitoria cuarta ${ }^{84}$ de la Ley 20/2009. De conformidad con su nuevo redactado, las actividades clasificadas en los Anexos III y IV de la Ley 20/2009 que a su entrada en vigor dispongan de licencia de actividades quedan convalidadas a los efectos de disponer de la licencia ambiental o de tenerse que realizar la comunicación ambiental y quedan excluidas de la obligación de llevar a cabo los controles periódicos. Por lo tanto, se excluyen de la obligación de adaptación a la Ley 20/2009, sin perjuicio de que deban cumplir con la normativa y los controles que puedan preverse en las correspondientes ordenanzas municipales o normativa sectorial. Asimismo, se prevé que por reglamento deberán establecerse las tipologías de control correspondientes.

B. La introducción de dos nuevas disposiciones transitorias en la Ley 9/2011

Como consecuencia de las importantes modificaciones que introduce en el régimen de intervención sobre las actividades regulado por la Ley 20/2009, la Ley 9/2011 incorpora dos disposiciones transitorias que hacen referencia al régimen jurídico aplicable a los expedientes relativos a la Ley 20/2009, iniciados a la entrada en vigor de esta ley de modificación (disposición transitoria primera) y al régimen transitorio aplicable a la Ley 20/2009 en relación con las actuaciones de control periódicas de las actividades ganaderas (disposición transitoria segunda).

La disposición transitoria primera prevé que los procedimientos relativos a actividades incluidas en el Anexo I.2 de la Ley 20/2009, iniciados antes de la entrada en vigor de la Ley 9/2011 y que con la nueva regulación se sujetan al régimen de licencia se someten al régimen legal vigente en el momento del inicio del procedimiento. Por lo tanto, si han empezado a tramitarse como autorización ambiental, se someten a este régimen. En cambio, si se trata de procedimientos relativos a actividades incluidas en el Anexo II de la Ley 20/2009 iniciados antes de la entrada en vigor de la Ley 9/2011 y que con la nueva regulación quedan sujetas al régimen de comunicación, se resuelven notificándole al interesado que la actividad se somete a dicho régimen $\mathrm{y}$, por consiguiente, no se continúa con la tramitación del procedimiento de licencia ambiental.

\footnotetext{
${ }^{84}$ Nótese que, con posterioridad, la disposición transitoria cuarta volverá a ser modificada por la Ley 5/2012. A esta segunda modificación nos referimos en el apartado IV.3.3.A de este trabajo.
} 
La disposición transitoria segunda establece que las actividades ganaderas que dispongan de autorización ambiental en la fecha de entrada en vigor de la Ley 9/2011 y que con la nueva regulación queden incluidas en el Anexo II de la Ley 20/2009, mantienen el régimen de control establecido por la autorización otorgada. Por su parte, las actividades que dispongan de licencia ambiental y que con la nueva regulación queden incluidas en el Anexo III, quedan sujetas al régimen de control de las actividades sometidas a comunicación que establece el artículo 73 si acreditan disponer de acta favorable obtenida en el control inicial y en el último control periódico realizado de acuerdo con la licencia otorgada. En caso contrario, mantienen el régimen de control que establece esta licencia.

\subsection{Otras disposiciones}

Además de las modificaciones analizadas, pueden citarse algunas otras. En primer lugar, se incluyen algunos cambios que afectan a la organización administrativa y, concretamente, a las Oficinas de Gestión Ambiental Unificada (OGAU). Así, se modifican los artículos 38 y 42. En el primero de ellos se introduce un nuevo apartado el 5- en el que se prevé que la OGAU dará apoyo y asistencia técnica a los órganos ambientales municipales y comarcales en la tramitación de las licencias ambientales, y también en los trámites de evaluación de la documentación ambiental aportada en el régimen de comunicación cuando estos órganos lo soliciten. Con ello se pretende dar uniformidad y homogeneidad en la tramitación de las licencias ambientales y en su contenido y prescripciones técnicas, respetando las competencias locales ${ }^{85}$. Y en el artículo 42.1, que prevé en la tramitación de las licencias ambientales de las actividades enumeradas en el Anexo VI la emisión de un informe preceptivo de la Administración hidráulica, de la Administración de residuos de Cataluña y del departamento competente en materia de protección del ambiente atmosférico, se recoge ahora que estos informes puedan ser solicitados por los entes locales directamente a las Administraciones competentes o bien a través de la OGAU donde se emplaza la actividad proyectada. Las OGAU unifican los diferentes informes emitidos en un único documento. Con esta medida se pretende facilitar la tramitación a los órganos municipales y consejos comarcales y eliminar duplicidad en los trámites, ya que se podrá centralizar la petición

\footnotetext{
${ }^{85}$ Vid. la Memòria general de modificació de la Llei 20/2009..., cit., p. 4.
} 
y la coordinación de los diferentes informes sectoriales en un solo órgano territorial. Además, desde la OGAU se podrá agilizar la tramitación y emisión de estos informes ${ }^{86}$. En segundo lugar, se modifica el artículo 81.1, en el que se recoge la tipificación de las infracciones muy graves con relación a la evaluación de impacto ambiental de las actividades de los Anexos I y II, con el fin de adecuar los diferentes supuestos de infracciones muy graves a las modificaciones introducidas en el articulado respecto a las actividades sometidas a evaluación de impacto ambiental y a las actividades sobre las cuales debe adoptarse una decisión previa de sometimiento a evaluación de impacto ambiental $^{87}$.

En tercer lugar, se modifica la disposición adicional cuarta y se introducen algunos cambios que afectan a la Comisión de Evaluación y Seguimiento, órgano adscrito al departamento competente en materia de medio ambiente y creado para la aplicación de esta Ley y para llevar a cabo las propuestas de incorporación o modificación de los Anexos de la Ley, además de servir como órgano de trabajo con un papel importante en el consenso y definición de las características básicas del propio desarrollo reglamentario con los agentes sociales y económicos ${ }^{88}$. Los cambios se materializan en la previsión de un mecanismo más ágil para su constitución y la determinación de su composición (en lugar de un reglamento, se prevé ahora que el Gobierno determine su composición) y en una reducción de las entidades representadas (ahora sólo se mencionan los diversos departamentos de la Generalitat, de los entes locales, de las agrupaciones empresariales y sindicales, y de los colegios y organizaciones profesionales más representativos relacionados con las materias reguladas por esta Ley -han desaparecido las referencias a las organizaciones profesionales agrarias más representativas y a la ingenierías y consultorías ambientales- y no se menciona ningún dato numérico en cuanto a los representantes -con anterioridad se indicaba un número no superior a veinte-).

En cuarto lugar, se añade una disposición adicional octava a la Ley 20/2009, mediante la cual se abre la puerta a que los colegios profesionales puedan ejercer funciones de

\footnotetext{
${ }^{86}$ Vid. la Memòria general de modificació de la Llei 20/2009..., cit., pp. 4-5.

${ }^{87}$ Vid. supra el apartado III, epígrafe 3.1, de este trabajo.

${ }^{88}$ Vid. la Memòria general de modificació de la Llei 20/2009..., cit., p. 5.
} 
comprobación y verificación documental ${ }^{89}$. De conformidad con esta disposición, los colegios profesionales competentes por razón de la materia "pueden ejercer funciones de comprobación y verificación documental, previas a las que ejerce la Administración, para dar la conformidad que los datos técnicos que se presentan a la Administración se ajustan a los requeridos para la actividad objeto de la autorización o la licencia y a los estándares de calidad de la documentación técnica aportada". En este sentido, "pueden establecerse convenios entre la Administración y los correspondientes colegios profesionales".

Por último, se modifica el Anexo VI, que recoge los informes preceptivos en materia de medio ambiente que deben concurrir en los procedimientos de licencia ambiental. De estas modificaciones, cabe destacar, en el apartado primero de este Anexo, la supresión de informe de la Administración hidráulica de Cataluña para las centrales hidroeléctricas de cualquier tamaño ${ }^{90}$. En segundo lugar, se añade, en el apartado segundo, un nuevo apartado d), en el que se fijan nuevos supuestos en que será preceptivo el informe de la Administración de residuos de Cataluña ${ }^{91}$. Y, en tercer lugar,

\footnotetext{
${ }^{89}$ En este punto, téngase en cuenta también el apartado 8 del artículo 10 de la Ley catalana 26/2010, de 3 de agosto, de régimen jurídico y de procedimiento de las Administraciones públicas de Cataluña (introducido por la Ley $10 / 2011$, de 29 de diciembre, de simplificación y mejora de la regulación normativa), que establece que "Las diferentes administraciones públicas catalanas pueden delegar funciones públicas en los colegios profesionales competentes por razón de la materia, especialmente las que se refieren a funciones de comprobación documental y técnica de los trabajos, y también, si procede, de excelencia profesional, preceptivos para la obtención de títulos administrativos habilitantes, o en otros procedimientos, tramitaciones administrativas o procesos de contratación. La delegación se formaliza mediante convenios de delegación que deben establecer sus condiciones y su alcance".

${ }^{90}$ Esta supresión se justifica por la Direcció General de Qualitat Ambiental en la Memòria general de modificació de la Llei 20/2009..., cit., p. 7, porque las centrales hidroeléctricas no figuran en ninguno de los códigos de actividades del Anexo II (actividades sometidas al régimen de licencia ambiental), por lo que no tendría sentido pedir informe a la administración hidráulica catalana. Sin embargo, el Consell Assessor per al Desenvolupament Sostenible desaconseja que se elimine la necesidad de que las centrales hidroeléctricas requieran informe de la Agencia Catalana del Agua, ya que considera que tienen una afectación en el medio hídrico (vid. Informe 2/2011, de 20 de junio de 2011, Consideracions..., cit., p. 4).

${ }^{91}$ El apartado d) exige este informe para las actividades comprendidas en el Anexo II, en los apartados 10.1, 10.2 (excepto desecherías), 10.5, 10.7 (excepto plantas de valorización de residuos de la construcción) y 10.8. La Direcció General de Qualitat Ambiental en la Memòria general de modificació de la Llei 20/2009..., cit., p. 8, justifica este cambio en la conveniencia de que haya un informe preceptivo de la Agencia de Residuos de Cataluña en los procedimientos de licencia ambiental de estas actividades, con el fin de incluir de forma homogénea las condiciones y obligaciones que debe cumplir cualquier gestor de residuos de procedencia no municipal. Este informe preceptivo "donaria seguretat a les empreses de gestió de residus i simplificaria els tràmits administratius, ja que només s'hauria de presentar una única sol-licitud a l'ajuntament i la seva llicència inclouria les condicions que regula la normativa de residus inclosa la inscripció al Registre de gestors". De este modo, se pretende poner fin a las consultas y dudas frecuentes planteadas por técnicos de ayuntamientos y de consejos comarcales en relación a qué condiciones deben incluirse en las licencias ambientales, especialmente en relación con la determinación del importe de la fianza y otras condiciones técnicas; y también a las dudas de las propias empresas de gestión de residuos en relación con el contenido de la licencia y la posterior inscripción en el registro de
} 
se modifica sustancialmente el contenido del apartado tercero ${ }^{92}$, que recoge los supuestos en que es preceptivo el informe del órgano ambiental del departamento competente en materia de protección del ambiente atmosférico. Con anterioridad a la reforma, la Ley preveía que requerían este informe las actividades sometidas a un régimen de intervención y control específicos por la legislación de referencia de calidad del aire y protección atmosférica y determinadas actividades del Anexo II $^{93}$. Tras la modificación de la Ley 9/2011, se cambia la sistemática y se concretan específicamente las actividades del Anexo II que requieren este informe, indicándose su código numérico, por lo que se gana en seguridad jurídica y se facilita a los ayuntamientos la tramitación de los procedimientos de licencia ambiental, al evitarles tareas interpretativas sobre si resulta o no exigible este informe.

\section{ANÁLISIS DE LAS MODIFICACIONES INTRODUCIDAS POR LA LEY 5/2012, DE 20 DE MARZO, DE MEDIDAS FISCALES, FINANCIERAS Y ADMINISTRATIVAS Y DE CREACIÓN DEL IMPUESTO SOBRE LAS ESTANCIAS EN ESTABLECIMIENTOS TURÍSTICOS}

En el DOGC de 23 de marzo de 2012 se publica la Ley 5/2012, de 20 de marzo, de medidas fiscales, financieras y administrativas y de creación del impuesto sobre las estancias en establecimientos turísticos ${ }^{94}$. Esta Ley, menos de tres meses después de la

gestores si no se incluyen en ella las prescripciones técnicas y administrativas necesarias. Vid. Memòria general de modificació de la Llei 20/2009..., cit., p. 7.

92 Este apartado vuelve a modificarse por la Ley 5/2012. Vid. infra el apartado IV, epígrafe 3.2 de este trabajo.

${ }^{93}$ La Ley 20/2009 se refería, en el Anexo VI, a las siguientes actividades del Anexo II: las actividades incluidas en los grupos A y B del catálogo de actividades potencialmente contaminantes de la atmósfera incluidas en el artículo 13.2 de la Ley estatal 34/2007, de 15 de noviembre, de calidad del aire y protección de la atmósfera; las afectadas por la normativa de comercio de derechos de emisión de dióxido de carbono (CO2); las actividades con instalaciones que, según el Decreto 319/1998, de 15 de diciembre, sobre límites de emisión para instalaciones industriales de combustión de potencia térmica inferior a $50 \mathrm{MW}$ e instalaciones de cogeneración, deban disponer de un plan de vigilancia de sus emisiones mediante emisiones en continuo; y las afectadas por el Real Decreto 117/2003, de 31 de enero, sobre limitación de emisiones de compuestos orgánicos volátiles causadas por el uso de disolventes en determinadas actividades.

${ }^{94}$ El Consell de Garanties Estatutàries ha emitido su Dictamen 4/2012, de 6 de marzo, sobre el Proyecto de Ley de medidas fiscales y financieras y de creación del impuesto sobre las estancias en establecimientos turísticos, a raíz de la solicitud presentada el 14 de febrero de 2012, a instancia de más de una decena parte de los diputados del Parlament del Grupo parlamentario de Iniciativa per Catalunya Verds-Esquerra Unida i Alternativa y de los Subgrupos parlamentarios de Solidaritat Catalana per la Independència y de Ciutadans, de acuerdo con lo previsto en los artículos 16.1.b) y 23.b) de la Ley 2/2009, de 12 de febrero, del Consell de Garanties Estatutàries. 
aprobación de la Ley 9/2011, vuelve a modificar la Ley 20/2009. Son pocas las modificaciones que se introducen en su articulado y principalmente hacen referencia al régimen de control periódico de determinadas actividades. Sin embargo, sí introduce algunos cambios relevantes por lo que respecta al régimen transitorio aplicable a las actividades que habían sido objeto de intervención administrativa ambiental antes de la entrada en vigor de la Ley 20/2009; y al régimen de adecuación de las actividades existentes incluidas en los anexos de la Ley 20/2009. A estas cuestiones nos referimos a continuación.

\section{De nuevo sobre la técnica legislativa utilizada: ahora una ley de acompañamiento de los presupuestos}

La nueva modificación de la Ley 20/2009 se ha realizado a través de la Ley de acompañamiento a la Ley de presupuestos de la Generalitat de Catalunya para el año 2012, la Ley 5/2012, de 20 de marzo, de medidas fiscales, financieras y administrativas y de creación del impuesto sobre las estancias en establecimientos turísticos. Se sigue, en consecuencia, con la tendencia apuntada de deficiente técnica legislativa, utilizándose esta vez una ley de acompañamiento, presentada junto con la Ley de presupuestos, para modificar un amplio número de normas con rango ley. Se trata de una Ley estructurada en tres títulos: el primero, dedicado a las medidas fiscales; el segundo, a las medidas relativas al régimen jurídico de las finanzas públicas y a las medidas en materia de función pública; y, el tercero, a la creación del impuesto sobre las estancias en establecimientos turísticos. Otra vez se incorpora una modificación de una Ley ambiental de gran trascendencia como es la 20/2009 en una macroley, formada por 116 artículos -amén de las 28 disposiciones adicionales, 11 transitorias, 6 derogatorias y 11 finales correspondientes-, que modifica un gran número de normas sobre las materias más variadas y cuyo objeto último no es ambiental, sino económico. Efectivamente, esta Ley debe situarse en el contexto de crisis económica y financiera por el que está atravesando en estos momentos Cataluña. Precisamente para hacer frente a algunos de los problemas estructurales de la economía catalana que han conducido a esta crisis y sus repercusiones - tal como pone de manifiesto el propio Preámbulo-, esta Ley incorpora algunas medidas urgentes que se dirigen, bien a incrementar los ingresos -entre estas, las medidas tributarias recogidas en los títulos I y III-, bien a reducir el 
gasto público -fundamentalmente las que recoge el título II, que pretenden racionalizar los recursos humanos al servicio de la Administración catalana-.

De nuevo debemos manifestar nuestra crítica más severa con relación a la técnica legislativa utilizada ${ }^{95}$. Otra vez una Ley ómnibus, en esta ocasión como Ley de acompañamiento a los presupuestos, permite de forma rápida y con escasas posibilidades de enmienda, introducir, tan solo tres meses después de la anterior, una nueva reforma de la Ley 20/2009. La utilización de esta técnica legislativa ha sido criticada por la doctrina ${ }^{96}$ y también ha sido objeto de análisis específico, en este caso concreto, por el Consell de Garanties Estatutàries. En su Dictamen 4/2012, de 6 de marzo, sobre el Proyecto de Ley de medidas fiscales y financieras y de creación del impuesto sobre las estancias en establecimientos turísticos, analiza la adecuación al bloque de la constitucionalidad de los preceptos cuestionados, desde la perspectiva de su inclusión en una ley de acompañamiento y del procedimiento legislativo para su tramitación. A pesar de las críticas que pueden verterse frente a este tipo de leyes desde el punto de vista del procedimiento legislativo, apelando a la jurisprudencia constitucional (fundamentalmente, las Sentencias 136/2011, de 13 de septiembre, y 176/2011, de 8 de noviembre), considera que el recurso a una ley de acompañamiento es legítimo y

"malgrat que el Projecte de llei dictaminat presenta un contingut heterogeni i multisectorial que contradiu l'article 101.1 RPC, aquest fet no comporta una vulneració del principi constitucional de seguretat jurídica establert a l'article 9.3 CE. I això és així en la mesura que el bloc de la constitucionalitat no prohibeix l'aprovació de lleis transversals ni preveu que el legislador només pugui aprovar normes homogènies que es refereixin a una matèria concreta ni que cada matèria hagi de ser objecte d'un projecte de llei independent (STC 136/2011, FJ 3)"97.

En definitiva, una Ley de acompañamiento de los presupuestos sirve para proseguir el atropellado proceso de reforma de la Ley 20/2009 y culminar su reforma, sin haberse utilizado un proceso legislativo pausado, que hubiese facilitado la discusión

\footnotetext{
${ }^{95}$ Vid. supra el apartado III, epígrafe 1, de este trabajo.

96 Sobre esta cuestión vid. CAZORLA PRIETO, L. M., Las llamadas Leyes de acompañamiento presupuestario. Sus problemas de constitucionalidad, Marcial Pons, Madrid, 1998.

${ }^{97} \mathrm{Vid}$. el fundamento jurídico $2^{\mathrm{o}}$, apartado 2.
} 
parlamentaria, tanto en la comisión correspondiente como en el propio Pleno ${ }^{98}$, en una materia de gran relevancia como es la de la prevención y control ambiental de actividades. Y la técnica seguida se entiende menos si cabe, si se tiene en cuenta que menos de tres meses antes ya se había procedido a una reforma de la Ley 20/2009 a través de otra Ley ómnibus y por el procedimiento de urgencia. Esta técnica legislativa utilizada resta coherencia a la normativa y dificulta su comprensión global, con el riesgo de producir inseguridad jurídica en los intérpretes y aplicadores de las normas, además de atentar contra el principio de especialización parlamentaria ${ }^{99}$. Y ello es así, aun cuando su utilización en este caso, como ha considerado el Consell de Garanties Estatutàries, no vulnere el principio de seguridad jurídica ni altere el procedimiento legislativo desde el punto de vista democrático.

\section{2. ¿Por qué una reforma tres meses después de la anterior?}

Quizás la primera pregunta que debiéramos realizarnos es el porqué de una nueva modificación de la Ley 20/2009 algo menos de tres meses después de la aprobación de la Ley 9/2011, coincidiendo con la aprobación de la Ley de Presupuestos de la Generalitat para $2012^{100}$. A diferencia de lo que sucedía con la Ley 9/2011, no hay aquí una memoria detallada del Departament de Territori i Sostenibilitat de la Generalitat justificando la reforma, ni nos ayuda en esta tarea la lectura del Preámbulo, toda vez que no se incluye ni una sola referencia específica en el mismo a la reforma de la Ley 20/2009 que ayude a comprender los motivos de su modificación.

Por otra parte, cabe tener en cuenta que la mayor parte de modificaciones que afectan a la Ley 20/2009 se han introducido en la Ley 5/2012 durante su tramitación parlamentaria, a raíz de una enmienda presentada por un Grupo parlamentario. Inicialmente, el Proyecto de Ley publicado en el Butlletí Oficial del Parlament de

\footnotetext{
${ }^{98}$ La Comisión competente para la tramitación de este Proyecto de Ley, dentro del Parlament de Catalunya, ha sido la Comissió d'Economia, Finances i Pressupost. Vid. el Acuerdo de la Mesa del Parlament, oída la Junta de Portavoces, sesiones de 20 de diciembre de 2011 (Butlletí Oficial del Parlament de Catalunya núm. 210, de 20 de desembre de 2011, p. 54).

${ }^{99}$ A esta cuestión ya nos hemos referido. Vid. supra el apartado III, epígrafe 1, de este trabajo. Sobre esta cuestión el Consell de Garanties Estatutàries advierte en su Dictamen 4/2012, ya citado, que los inconvenientes de las leyes de acompañamiento "provenen de l'heterogeneïtat de les matèries que s'hi regulen, tant per la major dificultat en la seva cerca, especialment pels ciutadans, que no poden identificar el contingut de la llei pel seu títol, com per la manca d'especialització en l'elaboració parlamentària" (fundamento jurídico $2^{\circ}$, apartado 2 ).

${ }^{100}$ Ley 1/2012, de 22 de febrero, de Presupuestos de la Generalitat de Catalunya para 2012.
} 
Catalunya únicamente incluía, en su artículo 74, la introducción de una nueva disposición adicional novena en la Ley 20/2009 ${ }^{101}$, con relación a la adecuación de las actividades existentes. Sin embargo, durante la tramitación parlamentaria el Grupo Parlamentario del Partit Popular de Catalunya presentó la enmienda núm. 513, de modificación del artículo 74, proponiendo la modificación de los artículos 56.3, 68.2, 71.2, la disposición transitoria cuarta y el Anexo VI de la Ley 20/2009, además de la introducción de la nueva disposición adicional novena ${ }^{102}$. Todos estos aspectos se recogieron en el Dictamen de la Comissió d'Economia, Finances i Pressupost sobre el proyecto de Ley ${ }^{103}$ y acabaron incorporándose, a raíz de esta enmienda, en el texto finalmente aprobado de la Ley 5/2012, si bien la nueva disposición adicional novena de la Ley 20/2009 acabó cambiando su ubicación y convirtiéndose en la disposición adicional vigesimosexta de la propia Ley 5/2012.

Teniendo en cuenta el contexto en el que se sitúa (una Ley de acompañamiento a los presupuestos, en una situación de grave crisis económica y financiera) y la ubicación de la reforma de la Ley 20/2009 dentro de la propia Ley 5/2012 (dentro del título II, de medidas relativas a las finanzas públicas, en el que se recogen medidas para la reducción y racionalización del gasto público), fácilmente puede intuirse que la finalidad de la reforma vuelve a ser, en buena medida económica (reducción de cargas administrativas y de costes económicos para los titulares de determinadas actividades). Sin embargo, también se aprovecha la reforma para clarificar algunas cuestiones de régimen transitorio e intentar cerrar el régimen de las actividades preexistentes a la Ley 20/2009.

\section{Análisis de las modificaciones más relevantes}

La Ley 5/2012 introduce pocas modificaciones en la Ley 20/2009. Se trata de modificaciones puntuales que afectan al régimen de control de determinadas actividades (arts. 56, 68 y 71), al régimen aplicable a las actividades que han sido objeto de intervención administrativa ambiental antes de la entrada en vigor de la Ley 20/2009 (disposición transitoria $4^{\mathrm{a}}$ ) y al Anexo VI. Sin embargo, lo más relevante de la Ley

\footnotetext{
${ }^{101}$ Vid. el Butlletí Oficial del Parlament de Catalunya núm. 210, de 20 de desembre de 2011, p. 44.

${ }^{102}$ Vid. el Butlletí Oficial del Parlament de Catalunya núm. 245, de 8 de febrero de 2012, pp. 107-108.

${ }^{103}$ Vid. el Butlletí Oficial del Parlament de Catalunya núm. 249, de 10 de febrero de 2012, pp. 3 y ss.
} 
5/2012 respecto a la materia que nos ocupa no son las modificaciones del articulado de la Ley 20/2009, escasas y para temas puntuales como hemos señalado, sino la inclusión, entre las disposiciones adicionales de la Ley 5/2012, de una -la vigesimosexta-, de gran trascendencia en cuanto afecta al régimen de adecuación de las actividades incluidas en los Anexos de la Ley 20/2009.

\subsection{Modificaciones en el régimen de control de determinadas actividades}

La Ley 5/2012 modifica los artículos 56.3, 68.2 y 71.2, para introducir cambios en el régimen de control de determinadas actividades de espectáculos públicos y actividades recreativas: las determinadas en el Anexo IV y que estén sujetas a licencia ambiental, por no estar sometidas en la normativa administrativa de espectáculos públicos y actividades recreativas a un régimen de licencia. El cambio que se introduce para estas actividades es la exclusión de la obligación de llevar a cabo controles periódicos. Se excluyen, por tanto, del régimen de control periódico aplicable a las licencias ambientales con arreglo a la Ley 20/2009 y se remite al reglamento el establecimiento de las tipologías de control pertinentes. Ello no significa que no se sometan a control, sino que el régimen de control que se aplique a estas actividades no será el de controles periódicos de las licencias ambientales, sino el que prevea a estos efectos un reglamento de futura aprobación. Será, pues, el reglamento de desarrollo de la Ley 20/2009, el que habrá de regular esta cuestión.

\subsection{Cambios en el Anexo VI}

La Ley 5/2012 vuelve a modificar el contenido del apartado tercero del Anexo VI, modificado pocos meses antes a través de la Ley 9/2011. Como ya se ha apuntado previamente $^{104}$, este apartado se refiere al informe del órgano ambiental del departamento competente en materia de protección del ambiente atmosférico que debe darse en los procedimientos de licencia ambiental de determinadas actividades. La modificación afecta a las actividades sometidas a este informe, ya que desaparecen de la lista anteriormente prevista $\mathrm{y}$, por lo tanto, de la exigencia de informe, determinadas

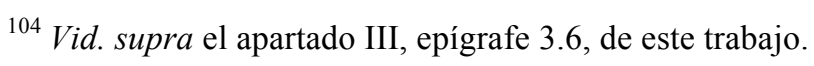


actividades que ahora están incluidas en el Anexo III y sometidas, por tanto, a comunicación ambiental, y no a licencia ambiental ${ }^{105}$.

\subsection{Cambios en el régimen transitorio y en el régimen de adecuación de actividades}

Una de las modificaciones más relevantes introducidas por la Ley 5/2012 en la Ley 20/2009 es la relativa al régimen transitorio, por cuanto vuelve a dar una nueva redacción -ya lo había hecho también la Ley 9/2011- a la disposición transitoria cuarta pocos meses después. Asimismo, aun cuando queda fuera de la Ley 20/2009, merece especial atención la Disposición adicional vigesimosexta de la propia Ley 5/2012, en la medida en que regula el régimen de adecuación de las actividades preexistentes a la entrada en vigor de la Ley 20/2009 e incluidas ahora en sus Anexos -aunque quizás por sistemática y mayor coherencia y seguridad jurídica habría podido incluirse como una disposición adicional o transitoria dentro de la propia Ley $20 / 2009^{106}-$.

\section{A. Una nueva modificación de la disposición transitoria cuarta de la Ley 20/2009}

En su nueva redacción, la disposición transitoria cuarta de la Ley 20/2009 recoge el régimen aplicable a las actividades que ya han sido objeto de intervención administrativa ambiental antes de su entrada en vigor y se estructura en tres apartados. En el primero, se prevé que las actividades que han sido objeto de intervención administrativa ambiental de acuerdo con la Ley 3/1998, de 27 de febrero, de la intervención integral de la Administración ambiental, pasan a regirse por las nuevas determinaciones de esta Ley.

En segundo lugar, los plazos de los controles periódicos de las actividades de los Anexos I y II son los fijados por el artículo 71.2 (las actividades del Anexo I.1, cada dos

\footnotetext{
${ }^{105}$ La redacción actual del apartado 3 del Anexo VI de la Ley 20/2009 prevé que este informe será necesario para las actividades comprendidas en el Anexo II, en los apartados 1.1, 1.12, 3.2, 3.4, 3.6, 3.9.b, 3.12, 3.19, 3.21, 3.30, 3.31, 3.33, 4.1.a, 4.1.b, 4.1.c, 4.1.d, 4.2, 4.5, 4.6, 4.7, 4.9, 4.12, 4.13, 4.14, 4.17, $5.6,5.8,5.9,5.10,5.11,5.14,5.15,5.16,6.1,6.2,7.9,8.2,9.2,9.4,10.1,10.4,10.5,10.9,10.10,10.11$, $12.2,12.3,12.4,12.6,12.16,12.22,12.31,12.39$ y 12.41. En relación con la redacción anterior, cabe destacar que han desaparecido las actividades con el código numérico 7.2.a), 7.2.b) y 11.4, anteriormente incluidas, pero que ahora se excluyen porque han pasado a estar incluidas en el Anexo III de la Ley 20/2009 y sometidas a un régimen de comunicación previa.

${ }^{106}$ De hecho, como ya se ha apuntado en este mismo apartado, en el epígrafe 2, en el Proyecto de Ley inicialmente publicado en el Butlletí Oficial del Parlament de Catalunya se recogía como una nueva disposición adicional novena, a incorporar a la Ley 20/2009.
} 
años; las de los Anexos I.2 y I.3, cada cuatro años; y las del Anexo II, cada seis años), salvo que se trate de actividades exentas de control periódico, de acuerdo con el artículo $71.3^{107}$.

En tercer lugar, las actividades clasificadas en los Anexos III y IV que a la entrada en vigor de esta Ley dispongan de licencia de actividades quedan convalidadas de tener que disponer de la licencia ambiental o de tener que realizar la comunicación ambiental y quedan excluidas de la obligación de llevar a cabo controles periódicos. Se prevé, sin embargo, que por reglamento, deben establecerse las tipologías de control pertinentes.

B. Nuevas previsiones en torno a la adecuación de las actividades existentes con anterioridad a la Ley 3/1998 e incluidas en los anexos de la Ley 20/2009 ¿Cierre definitivo del régimen de adecuación de las actividades preexistentes?

La disposición adicional vigesimosexta aborda un tema especialmente preocupante en Cataluña: el del régimen de adecuación de las actividades preexistentes a la Ley 20/2009. Uno de los temas más controvertidos y también uno de los principales retos durante la vigencia de la anterior Ley 3/1998, de 27 de febrero, fue precisamente el del régimen de adecuación de las actividades existentes a su entrada en vigor ${ }^{108}$. El proceso de adecuación se reveló especialmente complejo y los plazos inicialmente fijados como fecha límite fueron objeto de prórrogas sucesivas hasta desembocar en la aprobación de la Ley 4/2004, de 1 de julio, reguladora del proceso de adecuación de las actividades con incidencia ambiental a la Ley 3/1998 y el Decreto 50/2005, de 29 de marzo, que la desarrolla ${ }^{109}$.

\footnotetext{
${ }^{107}$ El artículo 71.3 de la Ley 20/2009 prevé que "Las actividades inscritas en el registro del sistema de ecogestión y ecoauditoría de la Unión Europea (EMAS) quedan exentas de control periódico, a excepción de los controles específicos de determinadas emisiones en los que se hayan establecido plazos particulares. La información necesaria respecto al cumplimiento de la autorización o la licencia ambientales debe aportarse junto con la actualización de la renovación de la acreditación del sistema de gestión ambiental, según el modelo determinado reglamentariamente, y debe presentarse copia al ayuntamiento correspondiente, excepto en el caso de las actuaciones en las que se hayan establecido otros plazos".

108 Vid. sobre esta cuestión PERDIGÓ SOLÀ, J., CHOY TARRÉS, A. i LIGÜERRE CASALS, J., Comentaris..., cit., p. 13.

${ }^{109}$ Sobre el régimen de adecuación a la Ley 3/1998 de las actividades con incidencia ambiental existentes antes de su entrada en vigor, vid. CASADO CASADO, L. y FUENTES GASÓ, J. R., Medi ambient $i$ ens locals, Cedecs, Barcelona, 2008, pp. 186-192.
} 
Varios años después, este tema todavía no se ha cerrado y la Ley 20/2009 llega cuando todavía no se había logrado la adecuación a la anterior Ley 3/1998 de todas las actividades preexistentes a la misma, a pesar de llevar aplicándose más de diez años. En su momento, la Ley 20/2009 no previó un proceso de legalización de actividades existentes que no dispusiesen de autorización o licencia ambiental. Tampoco derogó expresamente la Ley 4/2004, de 1 de julio, reguladora del proceso de adecuación de las actividades de incidencia ambiental, motivo por el cual sus previsiones serían de aplicación hasta que se hubiesen resuelto todos los expedientes derivados del proceso de adecuación y así se interpretaba por la Direcció General de Qualitat Ambiental del entonces Departament de Medi Ambient i Habitatge ${ }^{110}$. Ahora, con la Ley 5/2012, vuelve a plantearse la cuestión de las actividades preexistentes y su disposición adicional vigesimosexta articula una serie de criterios a aplicar a estas actividades, con el fin de cerrar de una vez por todas el régimen de adecuación de las actividades preexistentes incluidas en los Anexos de la Ley 20/2009. Esta disposición adicional se estructura en tres apartados. En el primero, prevé que las actividades existentes incluidas en el Anexo I de la Ley 20/2009 que estén en proceso de adecuación deben adecuarse antes del 31 de diciembre de 2012 a dicha ley, de acuerdo con la Ley 4/2004.

En el segundo, establece que las actividades existentes incluidas en el Anexo II de la Ley 20/2009 que dispongan de licencia municipal de actividades clasificadas para desarrollar su actividad actual, otorgada de acuerdo con el régimen vigente antes de la entrada en vigor de la Ley 3/1998, no deben someterse al proceso de adecuación que establecía la Ley 4/2004. El régimen de controles periódicos de estas actividades es el que establece la Ley 20/2009 y debe alcanzar la comprobación del cumplimiento de los requisitos de la normativa ambiental sectorial que les son aplicables. Estos controles deben iniciarse en 2013.

Y, en el apartado tercero dispone que las actividades existentes incluidas en los Anexos II y IV de la Ley 20/2009 que no dispongan de licencia municipal de actividades clasificadas para desarrollar su actividad actual, otorgada de acuerdo con el régimen vigente antes de la entrada en vigor de la Ley 3/1998, deben adecuarse antes del 31 de diciembre de 2013 a la Ley 20/2009, de acuerdo con la Ley 4/2004.

\footnotetext{
${ }^{110}$ Vid. el documento "Criteris a aplicar arran de l'entrada en vigor de la Llei 20/2009 de pevenció i control ambiental d'activitats".
} 


\section{CONSIDERACIONES FINALES}

El análisis de las recientes modificaciones de la Ley 20/2009, de 4 de diciembre, de prevención y control ambiental de las actividades de Cataluña, pone de manifiesto la inestabilidad de la normativa ambiental en momentos de crisis económica ${ }^{111}$. Bajo la justificación de la eliminación de trabas y demoras a favor de la promoción de la actividad económica y la reactivación de la economía se están aprobando, con una deficiente técnica legislativa, un gran número de modificaciones de leyes ambientales a la baja -no solo en Cataluña, sino también en otras Comunidades Autónomas y en el propio Estado ${ }^{112}-$, por lo que puede afirmarse que no corren buenos tiempos para la protección ambiental.

La modificación de la Ley 20/2009 se sitúa en este contexto, sin perjuicio de que también deban valorarse positivamente algunas modificaciones que suponen una mejora y de las que hemos dado cuenta en las páginas precedentes -por ejemplo, la clarificación de algunos aspectos de régimen transitorio-. Si, en su momento, esta Ley destacó por ir más allá de lo exigido estrictamente por la normativa básica estatal y por la legislación europea, ahora, tras las modificaciones operadas por las Leyes 9/2011 y $5 / 2012$ se ha dado un paso atrás y se han suprimido un buen número de normas adicionales de protección adoptadas (por ejemplo, la exigencia, en todo de caso de evaluación de impacto ambiental para las actividades del Anexo I.2; la incorporación de las mejores técnicas disponibles para las actividades de los Anexos I.2, I.3 y II; o la exigencia de autorización o licencia ambiental para actividades en las que no era obligatorio hacerlo) en pro de la agilización, de la simplificación administrativa y de la dinamización de la actividad económica. Escudándose en estas justificaciones, se procede a un retroceso del derecho existente y también a un retroceso de la protección del medio ambiente.

\footnotetext{
${ }^{111}$ Como pone de manifiesto PRIEUR, M., "El nuevo principio de "no regresión" en derecho ambiental", discurso pronunciado en el acto de investidura como Doctor Honoris Causa por la Universidad de Zaragoza, recogido en el libro Acto de investidura del grado de Doctor Honoris Causa. Manuel Losada Villasante, Michel Prieur, Frank T. Avignone, Prensas Universitarias de Zaragoza, Universidad de Zaragoza, 21 de junio de 2010, p. 60, "Los riesgos coyunturales como la reciente crisis económica o los riesgos políticos asociados a los cambios de gobierno constituyen una amenaza permanente para el derecho ambiental según su forma actual".

112 Buen ejemplo de ello es el Real Decreto-Ley 17/2012 de medidas urgentes en materia de medio ambiente (BOE num. 108, de 5 de mayo de 2012).
} 
La tendencia es clara: de un modelo de mayor protección se está pasando progresivamente a un modelo de intervención administrativa ambiental ceñido a lo estrictamente obligatorio, al mínimo exigible de acuerdo con la normativa estatal y europea. Sin embargo, como pone de manifiesto el Consell Assessor per al Desenvolupament Sostenible, "caldria aprofitar la capacitat de legislació autonòmica per a ampliar els supòsits on cal un procediment amb majors garanties de control $\mathrm{i}$ protecció ambientals d'aquelles activitats amb potencial impacte ambiental, com ja feia la Llei 20/2009",113.

Con la finalidad de simplificar el procedimiento y reducir cargas a los titulares de actividades y con el objetivo último de promoción de la actividad económica se están flexibilizando en buena medida el grado de protección ambiental, los sistemas de control de las actividades y los estándares ambientales. En este contexto, es imprescindible encontrar los adecuados mecanismos de equilibrio entre una ajustada carga administrativa y las garantías ambientales con el fin de garantizar la preservación del medio ambiente.

Más allá de la reforma de la Ley 20/2009 y situándonos en un marco más amplio, lo cierto es que la crisis económica está teniendo una gran incidencia en las políticas ambientales y en la legislación ambiental. LÓPEZ RAMÓN ${ }^{114}$, ante los problemas relativos a la crisis económica destaca "la frecuente inclinación de la balanza del interés público hacia el crecimiento y la marginación de las cuestiones ambientales". En su opinión, se trata de "Un fenómeno que se manifiesta bajo el manto protector de la crisis, pero que en verdad no es sino la manifestación de un proceso de desatención de la problemática ambiental, que encuentra ahora un buen momento para expresar, no sólo la inactividad, sino también actuaciones y soluciones abiertamente contrarias al principio de no regresión".

Cabe plantear en este punto que algunos autores están apelando al principio de no regresión ambiental como fundamento jurídico para evitar ciertos retrocesos del derecho ambiental. En este sentido, PRIEUR ha defendido la vigencia de un nuevo principio de "no regresión" en derecho ambiental. En su opinión, "La no regresión en derecho

\footnotetext{
${ }^{113}$ Vid. Informe del Consell Assessor per al Desenvolupament Sostenible 2/2011, de 20 de junio de 2011, Consideracions..., p. 3.

${ }^{114}$ LÓPEZ RAMÓN, F., "Introducción general: regresiones del derecho ambiental", en Observatorio de Politicas Ambientales 2011, Thomson-Aranzadi, Pamplona, 2011.
} 
ambiental se justifica, en primer lugar, a través de razones vinculadas al carácter finalista de este derecho. En tal sentido, es inherente a los objetivos perseguidos por el derecho ambiental. También se fundamenta en el derecho ambiental internacional, que de forma permanente establece la idea de que el objetivo es la progresión de la protección del medio ambiente en beneficio de la humanidad. Finalmente, la no regresión del derecho ambiental se verá legitimada, de forma jurídica, a través de los derechos humanos, que reconocen a ciertos derechos fundamentales un carácter irreversible que en el futuro también se podrán reconocer a favor del derecho ambiental" $" 115$.

\section{BIBLIOGRAFÍA}

AAVV, "Comentarios a la Ley 16/2002 de Prevención y Control Integrados de la Contaminación”, Revista Interdisciplinar de Gestión Ambiental, núm. 46, 2002.

ALONSO GARCÍA, M. C., "El procedimiento de otorgamiento de la autorización ambiental integrada", Justicia Administrativa. Revista de Derecho Administrativo, núm. 19, 2003, pp. 5-25.

BAUCELLS I LLADÓS, J. y VERNET I LLOBET, J. (coords.), La prevención y el control integrados de la contaminación, Marcial Pons, Madrid, 2004.

CASADO CASADO, L., Los vertidos en aguas continentales. Las técnicas de intervención administrativa, Comares, Granada, 2004.

CASADO CASADO, L. y FUENTES GASÓ, J. R., Medi ambient $i$ ens locals, Cedecs, Barcelona, 2008.

CAZORLA PRIETO, L. M., Las llamadas Leyes de acompañamiento presupuestario. Sus problemas de constitucionalidad, Marcial Pons, Madrid, 1998.

CHINCHILLA MARÍN, C., "La autorización ambiental integrada: la Ley 16/2002, de 1 de julio, de Prevención y Control Integrados de la Contaminación", Revista Andaluza de Administración Pública, núm. 47, 2002, pp. 43-72.

CHOY TARRÉS, A., L'autorització i la llicència ambiental: especial referència a la gestió municipal, Barcelona, Bayer Hermanos, 2000.

${ }^{115}$ PRIEUR, M., "El nuevo principio...”, cit., p. 65. 
DOMÍNGUEZ SERRANO, J., La prevención y el control integrados de la contaminación, Montecorvo, 2003.

ESTEVE PARDO, J., "La adaptación de las licencias a la mejor tecnología disponible", Revista de Administración Pública, núm. 149, 1999, pp. 37-61.

FORTES MARÍN, A., El régimen jurídico de la autorización ambiental integrada, Ecoiuris, Madrid, 2004.

GARCÍA URETA, A. (coord.), Régimen de prevención y control integrados de la contaminación, Gobierno de Aragón, Zaragoza, 2004.

LÓPEZ-JURADO ESCRIBANO, F. B. y RUIZ DE APODACA ESPINOSA, A., La autorización ambiental integrada. Estudio sistemático de la Ley 16/2002, de prevención y control integrados de la contaminación, Civitas, Madrid, 2002.

LÓPEZ RAMÓN, F., "Introducción general: regresiones del derecho ambiental”, en Observatorio de Politicas Ambientales 2011, Thomson-Aranzadi, Pamplona, 2011.

NOGUEIRA LÓPEZ, A., La termita Bolkestein. Mercado único vs. Derechos ciudadanos, Civitas, Madrid, 2012.

NOGUEIRA LÓPEZ, A., "Crisis económica y cambios estructurales en el régimen de ejercicio de actividades ¿Reactivación económica o pretexto desregulador”, en BLASCO ESTEVE, A. (coord.), El Derecho público de la crisis económica. Transparencia y sector público. Hacia un nuevo Derecho administrativo, Instituto Nacional de Administración Pública, Madrid, 2011, pp. 121-187.

PERDIGÓ SOLÀ, J., "La Ley estatal de transposición de la Directiva IPPC, sus efectos sobre la Ley catalana de intervención integral de la Administración ambiental, y sobre las competencias municipales", en Revista Aranzadi de Derecho Ambiental, núm. 2, 2002, pp. 77-91.

PERDIGÓ SOLÀ, J., CHOY TARRÉS, A. i LIGÜERRE CASALS, J., Comentaris a la Llei 20/2009, de 4 de desembre, de prevenció $i$ control ambiental de les activitats, Departament de Medi Ambient i Habitatge de la Generalitat de Catalunya, Barcelona, 2010 .

PERNAS GARCÍA, J.J., Estudio jurídico sobre la prevención de la contaminación industrial: la autorización ambiental integrada, Atelier, Barcelona, 2004. 
PONCE SOLÉ, J., "Prevención, precaución y actividad autorizatoria en el ámbito del medio ambiente. A propósito de los regímenes de autorización ambiental, licencia ambiental y comunicación previa de la Ley catalana 3/1998, de 27 de febrero, de la intervención integral de la Administración Ambiental", en Revista de Derecho Urbanístico y Medio Ambiente, núm. 183, 2001, pp. 147-192.

PRIEUR, M., "El nuevo principio de "no regresión" en derecho ambiental”, discurso pronunciado en el acto de investidura como Doctor Honoris Causa por la Universidad de Zaragoza, recogido en el libro Acto de investidura del grado de Doctor Honoris Causa. Manuel Losada Villasante, Michel Prieur, Frank T. Avignone, Prensas Universitarias de Zaragoza, Universidad de Zaragoza, 21 de junio de 2010, pp. 59-121.

REVUELTA PÉREZ, I., El control integrado de la contaminación en el derecho español, Marcial Pons, Madrid-Barcelona, 2003.

SOLER MATUTES, P., "La Ley de la Intervención Integral de la Administración Ambiental de Cataluña”, Revista de Derecho Ambiental, núm. 21, 1998, pp. 37-46.

VALENCIA MARTÍN, G. (coord.), Estudios sobre la prevención y control integrados de la contaminación, Aranzadi, Pamplona, 2003.

VALENCIA MARTÍN, G., “Aplicación y perspectivas de futuro de la Directiva sobre prevención y control integrados de la contaminación”, en Noticias de la Unión Europea, núm. 190, 2000, pp. 165-181.

VILLAREJO GALENDE, H., "Simplificación administrativa: silencio administrativo, licencias municipales y responsabilidad patrimonial. Comentario de los artículos 40 a 42, de la Disposición adicional $8^{\mathrm{a}} \mathrm{y}$ de la Disposición final $40^{\mathrm{a}}$ ", en BELLO PAREDES, S. (dir.), Comentarios a la Ley de Economía Sostenible, La Ley, Madrid, 2011, pp. $195-$ 222. 